\title{
UNA TEORÍA DE LA ARGUMENTACIÓN JURÍDICO-PENAL \\ Un primer esbozo sobre el ejemplo del bien jurídico protegido en el art. 318 bis del Código Penal español *
}

\author{
Fernando Guanarteme Sánchez Lázaro ** \\ Universidad de La Laguna
}

RESUMEN. El desarrollo de teorías de la argumentación jurídica, en el seno de la teoría general del Derecho, viene ofreciendo interesantes materiales para una racionalización del discurso jurídico. Sin embargo, la complejidad de lo jurídico precisa de mayores márgenes de rendimiento y con ello, probablemente también, de especialización. En las siguientes páginas se ofrece un primer esbozo de una - por el momento, tan sólo- posible teoría de la argumentación jurídico-penal.

Palabras clave: teorías de la argumentación jurídica, Derecho penal, teoría de la argumentación jurídico-penal.

ABSTRACT. The development of theories of legal argumentation within the general theory of law provides us with interesting materials for a rationalization of the legal discourse. However, the complexity of the subject requires a higher level of performance and probably more specialization as well. This is an attempt to outline - for the time being, only- a possible theory of argumentation for criminal law.

Keywords: theories of legal argumentation, criminal law, a theory of argumentation for criminal law.

* Fecha de recepción: 28 de febrero de 2008. Fecha de aceptación: 26 de marzo de 2008.

** El presente trabajo ha sido elaborado en el marco del proyecto de investigación «Derecho penal y nuevas tecnologías: sobre los intentos de adaptación del Derecho penal al desarrollo social y tecnológico, SEJ 2005 07489 MEC». 


\section{INTRODUCCIÓN}

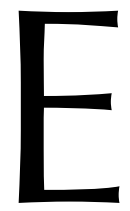

$\mathrm{n}$ un reciente trabajo, mantiene GARCía SÁNCHEZ que el bien jurídico protegido en el tipo básico del art. 318 bis del Código Penal español se encuentra en «los intereses estatales en el control de los flujos migratorios» ${ }^{1}$. La autora atiende en un primer momento, tanto a la voluntad del legislador como a razones de literalidad, y diferencia en su argumentación entre las perspectivas de lege lata y ferenda ${ }^{2}$. Desde el primer punto de vista, arguye igualmente lo que parece una interpretación sistemática de las distintas cláusulas de este precepto, si bien lo formula negativamente, esto es, como crítica a posiciones contrarias: «El mantener de lege lata que lo que se intenta proteger en el tipo básico son los derechos de los extranjeros (opinión contraria), tal y como aparece redactado el art. 318 bis. 1 y siguientes [...], conlleva problemas prácticos a la hora de determinar el ámbito punitivo de la conducta del tipo básico, pues los derechos de los extranjeros [...], donde se protegen realmente es en los tipos agravados, con lo que no imagino una afección a los derechos de los extranjeros sin que concurra alguna de las circunstancias agravantes de los n. ${ }^{\circ} 2$, 3,4 y 5 [...] Con lo que en la práctica se quedaría vacío de contenido el n. ${ }^{\circ} 1$ del 318 bis» ${ }^{3}$. En términos similares, sostiene AlONSO ÁlAMO «que la amplia formulación del tipo, las referencias al tráfico ilegal y, también, a la inmigración clandestina, la no exigencia de ánimo de lucro ni, menos aún, de la finalidad de explotación laboral, su excesiva formalización, obligan a sostener que el delito se orienta hacia la protección del interés estatal al control de los flujos migratorios»; matizando eso sí, «por muy cuestionable que pueda parecer la regulación y la orientación del delito desde una perspectiva político criminal» ${ }^{4}$.

${ }^{1}$ B. GARCÍA, 2005: «La pretendida protección jurídico-penal de los inmigrantes en el art. 318 bis del Código Penal», Anuario de Derecho Penal y Ciencias Penales, p. 852.

2 B. GARCía, cit., n. ${ }^{\circ}$ 1, pp. 849 y ss. En un sentido próximo, recientemente, también M. Alonso, 2007: «¿Protección penal de la dignidad? A propósito de los delitos relativos a la prostitución y a la trata de personas para la explotación sexual», Revista Penal, 19, pp. 16 y ss.; M. CANCIO y M. MARAVER, 2005: «El Derecho penal español ante la inmigración: un estudio político-criminal», en Derecho penal y política transnacional, Barcelona: Atelier, pp. 375 y ss.; J. HORTAL, 2007: «A vueltas sobre el bien jurídico-penal protegido en los mal llamados "delitos contra los derechos de los ciudadanos extranjeros" », en Política criminal y reforma penal, Montevideo-Buenos Aires: B de F, p. 475; J. LACRUZ, inédito: «Movimientos migratorios y Derecho penal. Sobre el bien jurídico protegido por el art. 318 bis del Código Penal español», ejercicio de habilitación, p. 15. De otra opinión J. SERRANO, 2002: «Los delitos contra los derechos de los ciudadanos extranjeros», en Inmigración y Derecho penal, Valencia: Tirant lo blanch, p. 329: «El concepto de bien jurídico tiene que ir necesariamente referido a la realidad social, y [...] no es creación del legislador, sino que es anterior al mismo y puede limitar su actividad», rechazando proposiciones formalistas.

3 B. GARCÍA, cit., n. ${ }^{\circ}$ 1, p. 850.

${ }^{4}$ M. Alonso, cit., n. ${ }^{\circ}$ 2, p. 16. En términos similares, entiende B. GARCíA, cit., n. ${ }^{\circ} 1$, p. 850, su propia postura como «insostenible», desde el punto de vista de lege ferenda, pues apunta que «el Derecho penal, en virtud de los principios de ultima ratio del Derecho y del principio de proporcionalidad no puede ser el instrumento para proteger esos intereses estatales que se plasman en el control de los flujos migratorios»; igualmente vid. pp. 851 y ss. Ilustrativo, también M. CANCIO y M. MARAVER, cit., n. ${ }^{\circ}$ 2, p. 346, para quien esta comprensión, su comprensión, resulta «perfectamente funcional desde la perspectiva de un "Derecho penal" del enemigo (o si se prefiere, de un Derecho penal estructuralmente ilegítimo)»; igualmente vid. pp. 375 y ss. Críticamente, sin embargo, STS 484/2007, de 29 de mayo, fundamento de derecho segundo, señalando que el bien jurídico protegido «no lo constituye sin más los flujos migratorios, atrayendo al Derecho interno las previsiones normativas europeas sobre tales extremos, sino que ha de irse más allá en tal interpretación — que supondría elevar a la categoría de ilícito penal la simple infracción de normas admnistrativas—»; STS 1087/2006, de 10 de noviembre, fundamento de derecho primero; STS 1465/2005, de 22 noviembre, fundamento de derecho séptimo: «No 
Frente a esta postura, sugiere VILLACAMPA ESTIARTE una comprensión del bien jurídico protegido que se concreta en los intereses «personales e individuales de quienes se veían sometidos a un traslado ilegal, que podría concretarse en la dignidad humana como base para el ejercicio del resto de derechos» ${ }^{5}$. De esta forma, se concibe el art. 318 bis como un «impedimento a la consideración de las personas como mercancía, en la interdicción del trato vejatorio que representa convertir en cosas a los seres humanos» ${ }^{6}$. En cuanto a la argumentación, la autora mantiene su postura no tanto sobre razones que cuestionan - luego, negativamente- los posicionamientos contrarios, como sobre aspectos satisfactorios de su solución. Así, apunta principalmente VILLACAMPA, que la comprensión que sugiere para el bien jurídico protegido atiende las exigencias de ultima ratio, frente a lo «que podría suponer la incriminación de una conducta contra un indicador macroeconómico, cual la defensa de las directrices de política de control de flujos migratorios fijada por el Estado español» ${ }^{7}$. Advierte, no obstante, que su propuesta, tendente a acercar el interés tutelado a los personales del sujeto sobre el que recae la acción, encuentra cierta resistencia en la ubicación sistemática del precepto: «Su inclusión tras el (Título) relativo a la tutela de los derechos de los trabajadores se compadece mejor con la afirmación de la protección de un interés económico» ${ }^{8}$. En un sentido no muy distinto, mantiene igualmente SERRANO PIEDECASAS, sobre la finalidad de la normativa de extranjería así como las consecuencias materiales de las conductas tipificadas, que el bien jurídico protegido no es otro que «el derecho que tiene todo emigrante legal a alcanzar una plena integración social»?

Finalmente, una tercera posición, matizada, ofrece RoDRÍGUEZ MONTAÑÉs, para quien los «derechos individuales de los ciudadanos extranjeros como colectivo, [...] constituyen sólo "bienes intermedios con función representativa" del bien jurídico institucionalizado, espiritualizado o de los "intereses difusos" del orden socioeconómico en sentido amplio (conjunto de condiciones e instituciones básicas para el mantenimiento del sistema socioeconómico vigente, tanto en su aspecto puramente económico como en la dimensión social del mismo), en la medida en que el fenómeno migratorio cons-

se trata, pues, de una mera protección penal del interés público en someter a control administrativo el citado y cada vez más frecuente flujo migratorio, cuya criminalización quebrantaría así el principio de intervención mínima del Derecho penal».

5 C. VILLACAMPA, 2004: «Consideraciones acerca de la reciente modificación del delito de tráfico de personas», Revista Penal, 14, p. 186; ID., 2005: «Título XV bis. Delitos contra los derechos de los ciudadanos extranjeros», en G. Quintero (dir.), Comentarios al nuevo Código Penal, 4. ${ }^{a}$ ed., Elcano: Aranzadi, p. 1668. En esta línea, entre otros, vid. F. DE LEÓN, 2003: Tráfico de personas e inmigración ilegal, Valencia: Tirant lo blanch, pp. 248 y ss.; M. GARCíA, 2004: «Esclavitud y tráfico de seres humanos», en Estudios penales en recuerdo del profesor Ruiz Antón, Valencia: Tirant lo blanch, pp. 375 y ss.; A. PÉREZ, 2006: «Delitos contra los derechos de los ciudadanos extranjeros», en Inmigración y sistema penal, Valencia: Tirant lo blanch, pp. 120 y ss.; ID., 2004: Globalización, tráfico internacional ilícito de personas y Derecho penal, Granada: Comares, pp. 170 y ss.

${ }^{6}$ Ibidem.

7 Para lo que entiende, debe bastar con el recurso al Derecho administrativo sancionador, C. VILLACAMPA, 2004: cit., n. ${ }^{\circ}$ 5, p. 187.

${ }^{8}$ C. VILlaCAMPA, 2004: cit., n. ${ }^{\circ}$ 5, p. 187. De otra opinión M. RodríGuez, 2001: Delitos contra los derechos de los ciudadanos extranjeros, Valencia: Tirant lo blanch, p. 55, quien apunta no obstante, la conveniencia de una reubicación sistemática, vid. p. 59.

9 J. SERRANO, cit., n. ${ }^{\circ}$ 2, p. 332. En nuestra jurisprudencia, expresamente, SAP 73/2005 Málaga, Melilla, de 28 de septiembre, fundamento de derecho primero: «En definitiva el bien jurídico protegido es el derecho del extranjero a una plena y efectiva integración social». En un sentido próximo, STS 1087/2006, de 10 noviembre, fundamento de derecho primero. Anteriormente, también SAP 15/2001 Málaga, Melilla, de 13 de marzo, fundamento de derecho primero; SAP 49/2004 Málaga, Melilla, de 30 julio, fundamento de derecho primero. 
tituye esencialmente un fenómeno socioeconómico y una cuestión de Estado» ${ }^{10}$. Esta autora sustenta su interpretación en la ubicación sistemática del precepto, concretamente, entre los delitos contra los derechos de los trabajadores y los relativos a la ordenación del territorio, patrimonio histórico y el medio ambiente ${ }^{11}$. Igualmente apunta, en esta misma línea, «que los derechos individuales de los inmigrantes (vida, libertad, integridad, dignidad) son tutelados directamente por los mismos preceptos penales que tutelan los derechos de los ciudadanos españoles, pues a los efectos de la protección penal no se establece ninguna diferenciación entre nacionales y extranjeros, en situación legal o ilegal» ${ }^{12}$.

Estos breves trazos permiten ya ofrecer una imagen orientativa de nuestro discurso jurídico-penal, particularmente el relativo a la denominada parte especial. Frente a la justificación — principalmente- genética, sistemática y semántica que ofrece GARCÍA SÁNCHEZ, y que lleva a esta autora a cuestionar de lege ferenda su propuesta de lege lata, la cual identifica el bien jurídico protegido con una pretendida voluntad del legislador de tutelar los «intereses estatales en el control de los flujos migratorios» ${ }^{13}$; opone C. VillaCAMPA, también de forma principal, razones de corte ético, teleológico y sistemático ${ }^{14}$, que articula sobre el denominado principio de ultima ratio ${ }^{15}$. Y una y otra autora ofrecen concreciones del denominado argumento consecuencialista general. En particular, VILLACAMPA pretende evitar, como vimos, «la incriminación de una conducta contra un indicador macroeconómico, cual la defensa de las directrices de política de control de flujos migratorios fijada por el Estado español en coordinación con el resto de países de la Unión» ${ }^{16}$; mientras que GARCía SÁNCHEZ esgrime, frente a las comprensiones que atienden a los derechos de los ciudadanos extranjeros, que éstas empu-

${ }_{10}$ T. RodRíGUEZ, 2001: «Ley de extranjería y Derecho penal», La Ley, 2, p. 1738, concluyendo que «nos encontramos ante un delito contra el orden socioeconómico (bien institucionalizado o espiritualizado, supraindividual y de carácter inmaterial), en que se tutela uno de los aspectos del mismo (el fenómeno migratorio), tutela que se lleva a cabo mediante la técnica de los delitos de peligro abstracto (ante la imposibilidad de tipificar la lesión o la concreta puesta en peligro) recurriendo a objetos o bienes intermedios (los derechos individuales de los inmigrantes como colectivo y el respeto de la regulación en esta materia) que tienen función representativa del bien institucionalizado o interés difuso». En un sentido próximo, también E. GARCÍA y J. RODRíGUEZ, 2002: «Delitos contra los derechos de los extranjeros (art. 318 bis del Código Penal)», Actualidad Penal, 2, p. 732, adscriben a esta figura «un carácter pluriofensivo, cuya defensa se centra tanto en el derecho del Estado a controlar las migraciones, como en los derechos individuales de los ciudadanos extranjeros», apuntando, en p. 733, «la vida, la salud o la integridad de las personas, así como la libertad individual de adultos y menores». En nuestra jurisprudencia, por ejemplo, SAP 63/2004 Madrid, de 12 de julio, fundamento de derecho cuarto: «El bien jurídico que se trata de proteger está constituido por dos tipos de intereses: el interés general de controlar los flujos migratorios evitando que esos movimientos sean aprovechados por grupos de criminalidad organizada, y el interés mediato de proteger la libertad, la seguridad, la dignidad y los derechos laborales de los inmigrantes»; SAP 42/2005 Badajoz, de 16 de diciembre, fundamento de derecho primero. Críticamente, sin embargo A. PÉREZ, 2006: cit., n. ${ }^{\circ}$ 5, pp. 117 y ss.

${ }^{11}$ Ibídem.

${ }^{12}$ Ibídem.

${ }^{13}$ B. GARCÍA, cit., n. ${ }^{\circ}$ 1, pp. 849, 850 y 852, por ejemplo.

${ }^{14}$ C. Villacampa, 2004: cit., n. ${ }^{\circ}$ 5, p. 187.

${ }^{15}$ C. Villacampa, 2004: cit., n. ${ }^{\circ}$ 5, p. 187. Al respecto apunta R. AleXY, 2003: «Die juristische Argumentation als rationaler Diskurs», en Elemente einer juristischen Begründungslehre, Baden-Baden: Nomos, p. 120, que en el presente contexto cobran especial significado los argumentos de principio («Prinzipienargumente»), lo cuales, en Estados democráticos constitucionales se apoyan esencialmente en principios constitucionales, «cuya aplicación implica, por lo general, en los casos difíciles, una ponderación que muestra su carácter de mandato de optimización».

${ }^{16}$ Ibídem. 
jan a subsumir en los subtipos agravados «toda conducta de favorecimiento y promoción a la inmigración clandestina» jurídico-penalmente relevante ${ }^{17}$. La diversidad de soluciones, así como de razones subyacentes, plantea una — pese a las apariencias- compleja cuestión: ¿qué postura adoptamos? En este sentido, a la aceptación de una u otra propuesta siguen consecuencias — costes y márgenes- en diversos planos problemáticos inherentes al discurso jurídico-penal. Así, con carácter general, se habla de racionalidad ética, teleológica, pragmática, jurídico-formal e incluso, comunicativa o lingüística ${ }^{18}$. Por otra parte, no se trata ni — según parece- debiera tratarse sólo de consecuencias. Pues cada postura muestra un diverso peso argumentativo. Luego, ¿deben prevalecer las razones genéticas, sistemáticas y semánticas que ofrece GARCÍA SÁNCHEZ frente al principio - de ultima ratio - sostenido por aquella otra autora? Y a esta última cuestión subyacen otras aún más complejas. Básicamente, las de «cómo analizar una argumentación jurídica, cómo evaluarla y (en definitiva), cómo argumentar en el Derecho» ${ }^{19}$.

El desarrollo de una teoría de la argumentación jurídica, en el seno de la teoría general del Derecho, viene proporcionando sugerentes materiales al respecto. Se trata, a grandes rasgos, de modelos de racionalidad que pretenden fungir como guías en la adoción de decisiones jurídicas ${ }^{20}$. Tales materiales, desde nuestra perspectiva, invitan a pensar - entre otras cosas- en un posible desarrollo de cánones y/o esquemas argumentativos jurídico-penales que, más allá de discriminar entre unas soluciones y otras, confieran a nuestra discusión mayores dosis de racionalidad y, quizá también, previsibilidad en sus soluciones. Particularmente, porque la ubicación del discurso jurídico-penal en el marco de una concreta constitución jurídica, abre la puerta a posibles prelaciones de variables axiológicas ${ }^{21}$. Y la incidencia esencial de las distintas premisas y conclusiones en valores como, por ejemplo, la libertad o la integridad física, facilita —aunque no sólo- una cuantificación de costes y márgenes iusfundamentales de las distintas soluciones. Éstas y otras razones nos llevan a pensar en la posibilidad de una teoría de la argumentación jurídico-penal que permita, a través de diversos instrumentos discursivos, una traducción y cuantificación de los distintos argumentos y soluciones en términos comparables de racionalidad - ¿de legitimidad?-. En cualquier caso, aquí de momento se tratará de establecer por esta vía el bien jurídico protegido en el art. 318 bis de nuestro Código Penal.

En el presente trabajo se aborda, por tanto, un estudio de esquemas y materiales para el desarrollo de lo que podría denominarse una teoría de la argumentación jurídico-penal. Para ello, comenzaremos analizando los márgenes de rendimiento de una de las teorías de la argumentación jurídica que más influencia ha ejercido en estas últimas décadas, la teoría

${ }^{17}$ B. GARCÍA, cit., n. ${ }^{\circ} 1$, p. 850.

${ }_{18}$ J. DíEz, 2003: La racionalidad de las leyes penales, Madrid: Trotta, passim. Con carácter general, M. ATIENZA, 1997: Contribución a una teoría de la legislación, Madrid: Civitas, passim.

${ }_{19}$ M. ATIENZA, 2006: El Derecho como argumentación, Barcelona: Ariel, p. 7.

${ }^{20}$ Ilustrativo M. ATIENZA e I. EsPEJO, 1989, en R. AleXY, Teoría de la argumentación jurídica. La teoría del discurso racional como teoría de la fundamentación jurídica, Madrid: Centro de Estudios Constitucionales, p. 15.

${ }^{21}$ En el sentido apuntado por R. AleXY, cit., n. ${ }^{\circ}$ 15, p. 120. Igualmente ilustrativo J. RAZ, 1997: «La intención en la interpretación», en J. MORESO y P. NAVARRO (trad. castellana), Doxa, n. ${ }^{\circ}$ 20, p. 202: «Las interpretaciones están sujetas a la evaluación como acertadas o erróneas (correctas o incorrectas), o como buenas o malas (o [...] aproximaciones de estos adjetivos, tales como "casi correcta")», y ello dentro de un contexto como el jurídico, que ofrece diversas posibilidades de enjuiciamiento. 
de la argumentación jurídica de R. AlEXY (II); sobre ello, nos aproximaremos a las particularidades del discurso jurídico-penal. Las especificidades de nuestra disciplina, y en concreto, la visibilidad de sus distintos costes (éticos, pragmáticos, teleológicos, etc.) favorecen el desarrollo de una teoría de la argumentación (III), pero ésta precisa ir más allá del señalamiento de lo discursivamente racional. El bien jurídico del art. 318 bis del Código Penal, ofrece una buena escusa para mostrar estas preocupaciones y revisar, de paso, anteriores pronunciamientos realizados en un momento poco dado a la reflexión ${ }^{22}$.

\section{MÁRGENES DE UNA TEORÍA DE LA ARGUMENTACIÓN JURÍDICA: EL MODELO DE R. ALEXY}

A finales de los años setenta, sobre la teoría del discurso racional de J. HABERMAS ${ }^{23}$, esboza AlEXY una sugerente explicación del discurso jurídico como un caso especial del discurso práctico general ${ }^{24}$. Según AlEXY, «lo que tienen en común los discursos jurídicos con el discurso práctico general consiste en que (para) ambas formas de discurso se trata de la corrección de enunciados normativos [...] tanto con la afirmación de un enunciado práctico general, como con la afirmación o pronunciamiento de un enunciado jurídico, se plantea una pretensión de corrección» ${ }^{25}$; si bien el discurso jurídico constituye «un caso especial, porque la argumentación jurídica tiene lugar bajo una serie de condiciones limitadoras», mencionando en particular, «la sujeción a la ley, la obligada consideración de los precedentes, su encuadre en la dogmática elaborada por la ciencia jurídica organizada institucionalmente, así como - lo que no concierne, sin embargo, al discurso científico-jurídico- las limitaciones a través de las reglas del ordenamiento procesal» ${ }^{26}$.

Sobre el desarrollo de los materiales para la formulación de una teoría del discurso práctico general, y a partir de ésta, las diversas reglas y formas del discurso jurídico, podemos remitirnos a otros lugares ${ }^{27}$. Aquí interesa situarse donde el profesor de Kiel

${ }^{22}$ Concretamente, F. SÁNCHEZ, 2002: «El nuevo delito de tráfico ilegal de personas», en Inmigración y Derecho penal, Valencia: Tirant lo blanch, pp. 287 y ss.

${ }_{23}$ Principalmente, cfr. R. AleXY, 1989: Teoría de la argumentación jurídica. La teoría del discurso racional como teoría de la fundamentación jurídica, en M. ATIENZA e I. EsPEJO (trad. castellana), Madrid: Centro de Estudios Constitucionales, pp. 131 y ss. Una exposición de conjunto ofrece M. ATIENZA, 1991: Las razones del derecho. Teorías de la argumentación jurídica, Madrid: Centro de Estudios Constitucionales, pp. 177 y ss.

${ }^{24}$ Ilustrativo R. AleXY, cit., n. ${ }^{\circ} 23$, p. 110: «El discurso moral es, más bien, una actividad guiada por reglas de tipo propio, en la que se trata del equilibrio racional de intereses», adscribiendo al discurso práctico racional la tarea de «la elaboración de las reglas que determinan esta actividad». Con carácter general, también vid. E. GARZÓN, 1998: «¿Puede la razonabilidad ser un criterio de corrección moral», Doxa, n. ${ }^{\circ} 21$ (2), pp. 147 y ss.

${ }^{25}$ R. Alexy, cit., n. ${ }^{\circ} 23$, pp. 35 y ss. Críticamente, también M. ATIENZA, cit., n. ${ }^{\circ} 23$, pp. 221 y ss., 225 y ss.; A. GARCÍA, 1999: «La tesis del caso especial y el positivismo jurídico», Doxa, n. ${ }^{\circ}$ 22, pp. 197 y ss.; K. GÜNTHER, 1995: «Un concepto normativo de coherencia para una teoría de la argumentación jurídica», en J. VELASCO (trad. castellana), Doxa, n. ${ }^{\text {os }} 17-18$, pp. 298 y ss. Por lo demás, apunta R. AlEXY, cit., n. ${ }^{\circ} 23$, p. 207, «que las dicusiones jurídicas se refieren a cuestiones prácticas, es decir, a cuestiones sobre lo que hay que hacer u omitir, o sobre lo que puede ser hecho u omitido»; más recientemente R. ALEXY, cit., n. ${ }^{\circ} 15$, p. 117, n. 16, señalando que en ello se unen «cuestiones y razones morales, éticas y pragmáticas».

${ }^{26}$ R. AlEXY, cit., n. ${ }^{\circ} 23$, pp. 35 y ss.; más recientemente, ID., cit., n. ${ }^{\circ} 15$, pp. 121 y ss.; señalando AlEXY en cualquier caso, cit., n. ${ }^{\circ} 23$, p. 38 , que «la amplia zona de lo meramente posible discursivamente, la provisionalidad de cualquier resultado, así como la necesidad de decidir en tiempo limitado numerosas cuestiones prácticas, hacen aparecer estas limitaciones no sólo como aceptables, sino también como razonables y necesarias».

${ }^{27}$ R. AleXY, cit., n. ${ }^{\circ}$ 23, passim. Sobre éste y otros modelos, véase M. ATIENZA, cit., n. ${ }^{\circ}$ 23, passim. 
concluye con sus reflexiones. Pues su pretensión resulta en exceso modesta como para ofrecer una solución al problema avanzado: «proponer reglas que, por una parte, sean tan débiles, es decir, que tengan tan poco contenido normativo que personas con concepciones normativas totalmente diferentes pudieran estar de acuerdo con ellas, pero que, por otra parte, sean tan fuertes que una discusión realizada de acuerdo con las mismas pueda ser calificada como "racional" ${ }^{28}$. Luego, no cabe esperar que la aplicación de sus reglas y formas discursivas permitan separar el trigo de la paja en la dogmática jurídico-penal, y señalar una entre las diversas posturas doctrinales relativas al bien jurídico protegido en el art. 318 bis del Código Penal. De hecho, apunta ALEXY, en relación «con las afirmaciones y decisiones jurídicas (que) no se pretende que éstas sean sin más correctas, sino sólo [...] correctas bajo el presupuesto del orden jurídico vigente»; lo cual «ocurre si se pueden fundamentar racionalmente teniendo en cuenta la ley, el precedente y la dogmática» ${ }^{29}$. Y sobre este tipo de enunciados se sustentan buena parte de las posiciones avanzadas al comienzo ${ }^{30}$; incluso comprensiones en gran medida contrapuestas como las de ALONSO ÁLAMO - predominantemente, sobre la formulación de la ley—y VilLACAMPA ESTIARTE — sobre principios dogmáticos. Si bien, el análisis de la justificación interna — esto es, de «si la decisión se sigue lógicamente de las premisas que se aducen como fundamentación»— ya cabría realizar algún descarte.

Así, por ejemplo, si se conviene en que razones de proporcionalidad aconsejan optar por un bien jurídico que favorezca un desarrollo del tipo como «injusto punible (merecedor de pena y necesitado de pena), como injusto agravado» ${ }^{31}$ — frente a otros tipos de ilícito-. Entonces, parece que estas mismas razones debieran concretarse en una comprensión del tipo como lesión o puesta en peligro de tal bien jurídico; esto es, como lesión o puesta en peligro de los concretos «valores y principios básicos de la convivencia social» $\gg^{32}$ tutelados — según tal comprensión- en este art. 318 bis. Sin embargo, ello no sucede siempre así. Me explico. Según SERRANo PiedECASAS, el bien jurídico protegido en este precepto se concreta en «el derecho que tiene todo emigrante legal a alcanzar una plena integración social» ${ }^{33}$. Pues bien, si A propone a B su transporte a España desde Marruecos, a cambio de una suma «en dinhares marroquíes equivalentes a entre 1.500 y 2.000 euros»; la conducta de A, el transporte de B a cambio de esta suma de dinero, puede verse como un menoscabo del patrimonio de este último e incluso, también, como un abuso de su situación personal, pues se apunta constituye «una cantidad que puede considerarse muy elevada» ${ }^{34}$ en su país de origen. Y si el transporte tiene lugar «en una débil embarcación ocupada por entre 20 y 30 personas más» ${ }^{35}$, en-

${ }^{28}$ R. AleXY, cit., n. ${ }^{\circ} 23$, p. 37, debilidad que se acentúa por el hecho de que algunas de tales reglas «sólo pueden ser cumplidas de manera aproximada».

${ }^{29}$ R. AleXY, cit., n. ${ }^{\circ} 23$, p. 314.

${ }^{30}$ Con carácter general, N. MACCORMICK, 1990: «Los límites de la racionalidad en el razonamiento jurídico», en M. AtIENZA y J. RuIZ (trad. castellana), Derecho y moral. Ensayos analíticos, Barcelona: Ariel, p. 22: «La racionalidad en el Derecho y en los procedimientos jurídicos es la primera virtud; pero hay otras más allá de ella».

31 En palabras de K. Amelung, 1991: «Contribución a la crítica del sistema jurídico-penal de orientación político-criminal de Roxin», en J. SILVA (trad. castellana), El sistema moderno del Derecho penal: Cuestiones fundamentales, Madrid: Tecnos, pp. 96 y ss.

32 Exposición de motivos, LO 10/1995, de 23 de noviembre, de Código Penal, párr. 1. ${ }^{\circ}$

33 J. SERRANO, cit., n. ${ }^{\circ} 2$, p. 332.

34 SAP Las Palmas 48/2004, de 22 de marzo, hechos probados primero.

35 SAP Las Palmas 48/2004, de 22 de marzo, fundamento de derecho tercero. 
tran en juego además, bienes jurídicos personales como la vida o la integridad física. Sin embargo, «el derecho que tiene todo emigrante legal a alcanzar una plena integración social» en España no se ve aquí perjudicado. Pues A, a tal efecto, se limita a introducir en nuestro país a un inmigrante cuya entrada — no hablemos ya de integraciónno es viable por cauces legales: de ahí las elevadas cantidades económicas y la necesidad de adquirir «la falsa documentación de identidad, supuestamente italiana» ${ }^{36}$. Es más, desde esta otra perspectiva, parece que el desplazamiento geográfico — su introducción irregular en España - favorece en alguna medida su posición jurídica — particularmente, en supuestos de permanencia irregular en aquel otro país- dada la posibilidad de mutar y regularizar ésta una vez en España accediendo, por ejemplo, a una autorización de residencia temporal ${ }^{37}$. Y todo ello puede reflejarse así:

1. El bien jurídico protegido debe facilitar una explicación de lo injusto como injusto merecedor de pena y necesitado de pena, como injusto agravado ${ }^{38}$.

2. La propuesta de SERRANO PIEDECASAS no permite una comprensión de estas figuras como injusto agravado, pues, las mismas pueden, incluso, favorecer —más que perjudicar- el interés que sugiere como objeto de tutela.

3. Luego «el derecho que tiene todo emigrante legal a alcanzar una plena integración social» no se presta a su adopción como bien jurídico protegido del art. 318 bis del Código Penal español. O de esta otra forma:

$$
\begin{aligned}
& O p \\
& q \rightarrow \neg \mathrm{p} \\
& \hline \neg q ;
\end{aligned}
$$

donde $O$ es un operador deóntico que se entiende como «es obligatorio que», $p$ representa razones de proporcionalidad y $q$ la propuesta de bien jurídico comentada, que dificulta atender a tales razones en el desarrollo del precepto.

Pero el análisis de «los esquemas formales de los razonamientos [...] con normas» tampoco permite «un tratamiento plenamente adecuado de los mismos, porque para ello habría que contar también con la perspectiva material y con la perspectiva pragmática» ${ }^{39}$. Asimismo, el modelo de ALEXY favorece en mayor medida, la explicación de

36 SAP Las Palmas 48/2004, de 22 de marzo, hechos probados segundo.

${ }^{37}$ Cfr. art. 31.3 Ley Orgánica 4/2000, de 11 de enero, sobre derechos y libertades de los extranjeros en España y su integración social, por ejemplo. En esta línea, aparentemente, también F. PÉREZ, 2006: Análisis dogmático y politico-criminal de los delitos contra los derechos de los ciudadanos extranjeros, Madrid: Dykinson, p. 43.

${ }^{38}$ Acentuando, así, la línea de ilícito material, frente a la correspondiente infracción administrativa, $c f r$. J. Cerezo, 2004: Curso de Derecho Penal español. Parte general I. Introducción, 6. ${ }^{a}$ ed., Madrid: Tecnos, p. 54.

${ }^{39}$ M. ATIENZA, cit., n. ${ }^{\circ} 19$, pp. 133 y, con carácter general, pp. 176 y ss.; apuntando en p. 118, que en los lenguajes naturales «no podemos hacer total abstracción de ciertas relaciones semánticas [...] ni tampoco del significado que nos viene dado por el contexto»; no obstante, en relación con las lógicas no monótonas, vid. pp. 119 y ss., 177, por ejemplo; concluyendo en cualquier caso, p. 121, que «si quiere mantener sus señas de identidad, entonces no puede dar cuenta de la realidad, tiene que prescindir, que hacer abstracción, de muchos aspectos consustanciales a la práctica argumentativa y respecto de los cuales la lingüística, la psicología, etc., suministran conocimientos esenciales [...] lo cual conduce, en definitiva, no a considerar que la lógica sea un conocimiento inútil o irrelevante [...] sino, simplemente, limitado». En esta línea, entre otros, L. LARENZ, 2001: Metodología de la ciencia del Derecho, en M. RodríGuEZ (trad. castellana), $2 .^{a}$ ed. (4. ${ }^{a}$ ed. alemana), Barcelona: Ariel, p. 173: «Un sistema conceptual, formado sólo según criterios lógico-formales, prescinde de las referencias valorativas que están detrás de las normas y, con ello, falsifica necesariamente la conexión de sentido pecu- 
problemas de estructura simple: «X ha realizado el acto $\mathrm{H}$; quien realiza actos como $\mathrm{H}$ debe ser condenado a la pena $\mathrm{P}$; por lo tanto, $\mathrm{H}$ debe ser condenado a la pena $\mathrm{P} \gg{ }^{40}$. Pero cuando se trata de establecer si procede imputar un resultado de muerte a un sujeto activo que circulando «bajo la influencia de bebidas alcohólicas y a una velocidad muy superior a la exigida para vías urbanas (más de $90 \mathrm{~km} / \mathrm{hora}$ )», se salta un semáforo en rojo y embiste lateralmente a un vehículo, cuando la muerte del sujeto pasivo se desencadena — también — por el rechazo de éste a una «transfusión [...] por ser testigo de Jehová» ${ }^{41}$, el análisis lógico no resuelve gran cosa ${ }^{42}$. ALEXY advierte estos extremos, y en los supuestos de complejidad problemática, apunta que «la decisión depende entonces de la práctica de distintas ponderaciones y de la posibilidad de identificar en qué medida los diversos juegos favorecen o perjudican realmente a los principios que entran en juego» ${ }^{43}$. De esta forma parece, diferencia los problemas -más simplesde subsunción de los de ponderación, en los que se trataría de establecer, a través de diversas leyes, el grado de intervención en uno de los principios afectados, de satisfacción del segundo y de una ponderación de ambas premisas; básicamente: «Si la importancia de la satisfacción del principio contrario justifica la afectación o la no satisfacción del otro» ${ }^{4}$. Surge la duda de si más allá de estos parámetros, y en definitiva, de la ponderación sin más de los principios en juego, es posible el desarrollo de otros modelos de solución.

\section{HACIA UNA TEORÍA DE LA ARGUMENTACIÓN JURÍDICO-PENAL}

Según se avanzó más arriba una teoría de la argumentación jurídica debiera ofrecer, básicamente, tres respuestas; esto es: «Cómo analizar una argumentación jurídica, cómo evaluarla y cómo argumentar en el Derecho» ${ }^{45}$. Sin embargo, los materiales co-

liar del Derecho, la cual no es de naturaleza lógico-formal, sino teleológica»; J. MORESO, P. NAVARRO y M. REDONDO, 1992: «Argumentación jurídica, lógica y decisión judicial», Doxa, n. ${ }^{\circ} 11$, pp. 255 y 259: «La lógica sólo proporciona un criterio para controlar la validez de una inferencia»; G. RODRíGUEZ, 1988: Aplicación judicial del Derecho y lógica de la argumentación jurídica, Madrid: Civitas, pp. 14 y ss., 23 y ss., 36,53 y ss., 61 y ss.; J. WRÓBLEWSKI, 1985: Constitución y teoría general de la interpretación jurídica, en A. AZURZA (trad. castellana), Madrid: Civitas, p. 61.

${ }^{40}$ M. ATIENZA, cit., n. ${ }^{\circ} 19$, p. 65.

${ }^{41}$ Antecedente de hecho primero, SAP Gipuzkoa (Sección 2. ${ }^{a}$ ), de 20 de febrero de 2003.

${ }^{42}$ Con mayores matices, J. HRuSCHKA, 1981: «Das Strafrecht neu durchdenken!», Goltdammer`s Archiv, pp. 241 y ss.; ID., 1984: «Kann und sollte die Strafrechtswissenschaft systematisch sein?», Juristen Zeitung, pp. 7 y ss.

${ }_{43}$ R. ALEXY, 2002: «Epílogo a la teoría de los derechos fundamentales», en C. BERNAL (trad. castellana), Revista española de Derecho constitucional, n. ${ }^{\circ} 66$, p. 25.

${ }^{44}$ R. AleXY, cit., n. ${ }^{\circ} 43$, pp. 31 y ss. También, en relación con la importancia de las distintas formas de argumento, ID., cit., n. ${ }^{\circ}$ 23, p. 239: «(J. 8) La determinación del peso de argumentos de distintas formas debe tener lugar según las reglas de ponderación», señalando al respecto que «tales reglas sólo pueden desarrollarse con referencia a determinados contextos de interpretación y determinados sectores del Derecho». En esta línea, M. ATIENZA, cit., n. ${ }^{\circ}$ 19, p. 232: la atribución de «peso depende de diversos factores que no pueden determinarse (cuáles son esos factores y cuál es su importancia) de antemano. Hay, por supuesto, ciertos elementos de carácter formal [...] y criterios de carácter más o menos material (el principio de universabilidad, de coherencia, etc.) que deben respetarse para que la ponderación pueda verse como una operación racional, pero su aplicación, en cada caso deja, sin duda, un amplio espacio para la deliberación. Además, esos criterios no son quizás exactamente los mismos en cada sistema o cultura jurídica».

${ }^{45}$ M. ATIENZA, cit., n. ${ }^{\circ} 19$, p. 7. 
mentados hasta ahora, a través de diversas formas y reglas discursivas, sólo permiten ofrecer una limitada respuesta a la cuestión del análisis y la forma argumentativa. Con ello no se cuestiona la importancia de un análisis formal del iter argumentativo ${ }^{46} \mathrm{o}$ del establecimiento de los márgenes de lo discursivamente racional, como en el modelo de AlEXY. Se pretende, simplemente, señalar que buena parte del discurso jurídico tiene lugar dentro de estos márgenes ${ }^{47}$, o en otros términos: que incluso un criterio como el de la racionalidad se muestra demasiado tosco como para captar ulteriores planos significativos de la argumentación jurídica. Y ello particularmente, porque la ubicación de este discurso dentro de un concreto marco jurídico y su — por lo general, mayor o menor- vinculación a unas u otras partes del mismo debiera permitir, parece, mayores precisiones ${ }^{48}$. Por ejemplo, el desarrollo de diversos parámetros de racionalidad que faciliten un enjuiciamiento de los costes y rendimientos —éticos o pragmáticos, entre otros supuestos- de uno u otro tipo de discurso. De hecho, en los últimos años, se vienen realizando importantes esfuerzos al respecto.

\section{1. ¿Cómo analizar una argumentación de Derecho?}

El desarrollo de una teoría de la legislación en el seno de la teoría del Derecho, viene sintetizando materiales que, más allá de perspectivas formales y dentro del marco de lo jurídicamente posible, favorecen el análisis de los diversos planos de racionalidad presentes en el discurso legislativo. Sobre ello, recientemente, he tratado de esbozar

46 Así, apunta M. ATIENZA, cit., n. ${ }^{\circ}$ 19, p. 180, que «la lógica no refleja cómo de hecho argumentamos, pero nos da moldes con los que reconstruir esa argumentación, una vez que ha tenido lugar [...]. Desde el punto de vista de la lógica deductiva, la mayor parte de los argumentos que efectuamos en la vida cotidiana (y en el Derecho) son entimemáticos, esto es, no explicitan todas sus premisas. La lógica deductiva es un método para hallar las premisas que faltan y, en consecuencia, para controlar la cantidad de los argumentos, pues nos lleva a plantearnos la cuestión de hasta qué punto esas premisas implícitas son o no aceptables»; igualmente, op. cit., p. 273, situando el fundamento de estas comprensiones formales en «la esperanza fundada en que, si se presenta adecuadamente, la verdad y la justicia prevalecen sobre sus contrarios o dicho de otra manera, cierto optimismo en el género humano». Últimamente, también R. ALEXY, 2003: «Die logische Analyse juristischer Entscheidungen», en Elemente einer juristischen Begründungslehre, Baden-Baden: Nomos, pp. 9, 34 y ss.: «Para la adecuada reconstrucción de la justificación externa la lógica es, en general, necesaria, pero no suficiente. Suficiente sería sólo una teoría de la argumentación jurídica cuyo fundamento irrenunciable sería la lógica, pero fuese bastante más allá de ésta». En relación con la lógica borrosa, igualmente T. MAZZARESE, 1996: «Lógica borrosa y decisiones judiciales: el peligro de una falacia racionalista», en J. MORESO (trad. castellana), Doxa, n. ${ }^{\circ} 19$, pp. 225 y ss.

${ }_{47}$ Expresamente, R. ALEXY, cit., n. ${ }^{\circ} 23$, p. 37: «Hay que concluir que son posibles varios resultados». En el mismo sentido, A. AARNIO, 1987: «Sobre la ambigüedad semántica en la interpretación jurídica», en J. ÚBEDA (trad. castellana), Doxa, n. ${ }^{\circ}$ 4, p. 112.

${ }^{48}$ Cfr. R. AleXY, cit., n. ${ }^{\circ}$ 23, p. 206. Ilustrativo, también A. AARNIO, cit., n. ${ }^{\circ} 47$, p. 112: «La interpretación jurídica, por otra parte, se caracteriza por la existencia de fundamentos de autoridad para la interpretación [...] así como de principios que rigen su utilización, que han sido interiorizados por la comunidad»; K. LARENZ, cit., n. ${ }^{\circ} 39$, p. 337, apuntando en concreto que «entre los principios ético-jurídicos, a los que ha de orientarse la interpretación, corresponde una importancia considerable a los principios elevados a rango constitucional», deduciendo en consecuencia, p. 338, que «entre varias interpretaciones posibles [...], siempre obtiene preferencia aquella que mejor concuerda con los principios de la Constitución»; J. WRÓBLEWSKI, cit., n. ${ }^{\circ}$ 39, p. 49, «(DI1-10): A una regla legal se le debería atribuir un significado de modo que la regla fuera lo más coherente posible con un principio válido del derecho», explicando al respecto, que «a las reglas constitucionales se las considera como principios jerárquicamente más altos que otras reglas legales». Con carácter general, también vid. J. RAZ, 1991: Razón práctica y normas, en J. RuIZ MANERO (trad. castellana), Madrid: Centro de Estudios Constitucionales, pp. 39 y ss.; posteriormente, también, pp. 231 y ss. 
una respuesta a la cuestión, planteada por REVERÓN PALENZUELA, relativa a la posibilidad de una evaluación racional de las leyes penales ${ }^{49}$. En la medida en que el discurso legislativo constituye sólo una de las posibles manifestaciones del discurso jurídico, parece que tales materiales debieran prestarse también, para una explicación de cómo analizar una argumentación jurídica que se orienta no ya a la creación, sino a la interpretación y aplicación del Derecho. La proximidad de contextos entre los discursos legislativo y hermenéutico, se traduce en una - mayor o menor-coincidencia de planos de racionalidad, particularmente a nivel ético y teleológico; sin perjuicio de los inevitables y significativos matices reflejo de las diferencias entre una y otra fase - pre y postlegislativa - del discurso jurídico: ¿Cómo y en qué medida incide la racionalidad lingüística en los márgenes de racionalidad de un discurso dogmático?, ¿dónde se pondera el grado de sujeción al tenor literal?, por poner dos ejemplos.

En una pequeña monografía, titulada «Contribución a una teoría de la legislación», presenta M. ATIENZA un concepto de agudas aristas como el de racionalidad, en forma de esquema operativo mediante el señalamiento y relación de los principales planos problemáticos que encuentra el legislador en la formulación de sus decisiones ${ }^{50}$. ATIENZA disecciona este término en cinco planos de racionalidad; si bien la preeminencia del nivel de racionalidad ética sobre los siguientes ha llevado entre nosotros a DíEz RIPOLLÉs, a proponer una inversión de la estructura del modelo, que antepone éste a los restantes contenidos ${ }^{51}$, a saber: racionalidad ética, teleológica, pragmática, jurídico-formal y comunicativa o lingüística. De este modo, resulta un esquema que facilita el análisis tanto interno - esto es, diferenciado e individual de cada uno de estos cinco peldañoscomo externo - mediante su interrelación- de los diversos contenidos, dilucidándose a través de todos ellos la cuestión de la eficiencia —o evaluación-, en términos de racionalidad. Pero veamos primero, cómo analizar una argumentación jurídica.

En el nivel de racionalidad ética, se propone un análisis de la decisión jurídica desde la perspectiva de principios como la libertad, igualdad, justicia o - incluso también- cuestiones de competencia. Con carácter general, se nos remite al «sistema de creencias, cultural e históricamente condicionado, que sustenta a una determinada colectividad» ${ }^{52}$. Se reclama un papel rector en este plano de la filosofía del Derecho ${ }^{53}$. También se advierte un importante marco referencial en el concreto cuadro constitucional $^{54}$. En este primer plano se trata en definitiva, de establecer si la concreta solu-

49 F. SÁNCHEZ, 2006: «¿Cómo se valora un texto normativo? Sobre el ejemplo del reciente Anteproyecto de Ley Orgánica por la que se modifica la LO 5/2000 reguladora de la responsabilidad penal de los menores», Anales de la Facultad de Derecho de la Universidad de La Laguna, pp. 187 y ss.

${ }^{50}$ Ampliamente véase M. ATIENZA, cit., n. ${ }^{\circ} 18$, passim, particularmente pp. 27 y ss., 81 y ss., 91 y ss. Anteriormente ya, ID., cit., n. ${ }^{\circ} 23$, p. 238; señalando en p. 228, la desatención en ALEXY de la «lógica de la argumentación que se lleva a cabo en el establecimiento de las normas jurídicas». Posteriormente, desde nuestra disciplina, también J. DíEZ, cit., n. ${ }^{\circ}$ 18, passim, y especialmente pp. 86 y ss., 109 y ss.; ID., 2005: «La racionalidad legislativa penal: contenidos e instrumentos de control», en La política legislativa penal en occidente. Una perspectiva comparada, Valencia: Instituto Andaluz Interuniversitario de Criminología-Tirant lo blanch, pp. 281 y ss.

${ }^{51}$ Con razón, J. DíEZ, cit., n. ${ }^{\circ}$ 18, p. 91, señalando, no obstante, en p. 97, que la «idea de eficiencia» apunta a «un equilibrio óptimo entre las diversas racionalidades, de modo que en ningún caso el aseguramiento de un determinado nivel de racionalidad conlleve la anulación de otro u otros»; ID., cit., n. ${ }^{\circ}$ 50, p. 281.

52 J. DíEZ, cit., n. ${ }^{\circ}$ 18, p. 92; ID., cit., n. ${ }^{\circ}$ 50, p. 281.

53 M. ATIENZA, cit., n. ${ }^{\circ} 18$, pp. 39 y ss.

54 Advirtiendo el carácter instrumental de la Constitución (en este sentido, con razón J. DíEZ, cit., n. ${ }^{\circ}$ 18, p. 180; con carácter general, señalando la independencia de las reflexiones ético-normativas de todo derecho 
ción jurídica constituye una decisión proporcional o satisface adecuadamente el principio de culpabilidad, por poner dos ejemplos ${ }^{55}$. DíEz RIPOLLÉs propone, desde nuestra disciplina, una estructura de la racionalidad ética a partir de tres clases de principios $^{56}$. Ciertamente, se trata de una estructura pensada para el discurso legislativo. Sin embargo, las pautas que rigen la elección de los contenidos, o principios de protección, fungen igualmente en la fase de interpretación y aplicación del Derecho. Pues de eso se trata, aunque no sólo, en la teoría del bien jurídico ${ }^{57}$, por poner otro ejemplo. Este penalista distingue - en este primer grupo, principios de protección- entre los denominados principios de lesividad, esencialidad o fragmentariedad, interés público y de correspondencia con la realidad. Apunta al respecto, la necesidad de limitar la tutela a «los presupuestos esenciales para la convivencia externa y la limitación de sus intervenciones a los ataques más intolerables a tales presupuestos imprescindibles» ${ }^{58}$, matizando que mediante la referencia subrayada — a la convivencia externa — «se quiere decir que los comportamientos frente a los que ha de intervenir el Derecho penal deben afectar a las necesidades del sistema social en su conjunto» ${ }^{59}$. Se advierte ya la convergencia entre estos contenidos y algunas de las razones expuestas anteriormente. Por ejemplo, la alusión a «la infracción del principio de ultima ratio que podría suponer la incriminación de una conducta contra un indicador macroeconómico, cual la defensa de las directrices de política de control de flujos migratorios fijada por el Estado español» ${ }^{60}$. En un segundo grupo, recoge los denominados principios de responsabilidad. Se trata ahora de los presupuestos de imputación jurídico-penal, esto es, de «las cualidades esenciales que la sociedad considera que deben concurrir para que a una persona se le pueda exigir responsabilidad por un comportamiento afectante a tales objetos de protección» ${ }^{61}$. DíEZ RIPOLLÉS sitúa aquí los principios de certeza o seguridad jurídica, de responsabilidad por el hecho, de imputación, reprochabilidad o culpabilidad y de jurisdiccionalidad. Señala igualmente, la necesidad de diferenciar el principio de seguridad jurídica del de legalidad, principio este último cuya trascendencia «no alcanza el nivel básico de racionalidad ética», en la medida en que nuestra sociedad ni la cultura

positivo, entre nosotros ya J. HRUSCHKA, 1981, cit., n. $^{\circ}$ 42, p. 237), pero también su potencialidad discursiva. En este sentido, propone atender y valorar los objetivos jurídico-penales «como cristalización de las decisiones de política criminal», entre otros aspectos, en función de su vinculación al respeto de los derechos fundamentales J. VogeL, 2005: «Evaluación de los sistemas penales. Contribución a una Política criminal racional», en La política legislativa penal en occidente. Una perspectiva comparada, Valencia: Instituto Andaluz Interuniversitario de Criminología-Tirant lo blanch, pp. 270 y ss.

${ }^{55}$ El carácter de estas razones, permite por otra parte, rechazar su contigencia. Así, cuando se niega «que el razonamiento justificatorio del juez deba, por razones lógicas, utilizar una premisa moral», J. MORESO, P. NAVARRO y M. REDONDO, cit., n. ${ }^{\circ}$ 39, p. 252, ello sólo puede aceptarse en el sentido de su utilización expresa, esto es, en el caso de razonamientos entimemáticos — razonamientos correctos que no muestran tales razones- por encontrar ya un grado de satisfacción aceptable.

${ }_{56} \mathrm{~J}$. DíEZ, cit., n. ${ }^{\circ} 18$, pp. 136 y ss.

57 Sin que se pretenda la equiparación del principio de su exclusiva protección con el principio de lesividad, con razón J. DíEZ, cit., n. ${ }^{\circ}$ 18, p. 139.

${ }^{58} \mathrm{~J}$. DíEZ, cit., n. ${ }^{\circ} 18$, p. 141. Al respecto, en relación con el principio de proporcionalidad en la doctrina constitucional, igualmente vid. S. MIR, 2002: «Principio de proporcionalidad y fines del Derecho penal», en Estudios Jurídicos en Memoria de José María Lidón, Bilbao: Universidad de Deusto, pp. 358 y ss. Con carácter general G. LOPERA, 2006: Principio de proporcionalidad y ley penal, Madrid: Centro de Estudios Políticos y Constitucionales, passim.

${ }^{59}$ J. DíEZ, cit., n. ${ }^{\circ} 18$, p. 144.

${ }^{60}$ C. VillacAmpa, 2004: cit., n. ${ }^{\circ}$ 5, pp. 186 y ss.

${ }^{61}$ J. DíEZ, cit., n. ${ }^{\circ} 18$, pp. 145 y ss. 
jurídica vigente «parecen conmoverse por el socavamiento que el principio de legalidad formal está sufriendo en diversos frentes» ${ }^{62}$. Finalmente, en tercer lugar, habla también de los principios de la sanción, donde resume una serie de «pretensiones éticas que quieren asegurar que los efectos sociales a conseguir con las penas no van a superar los límites del ejercicio del poder acordados socialmente, esto es, que la protección frente a aquellos daños no se desnaturalice mediante un modelo de intervención penal que termine incidiendo de manera socialmente inasumible sobre los planes de vida de los ciudadanos» ${ }^{63}$. Subsume aquí los principios de humanidad de las penas, teleológico o de los fines de la pena, de proporcionalidad y de monopolio punitivo estatal. En cuanto al contenido del tercero, el principio de proporcionalidad, «recoge la creencia de que la entidad de la pena, esto es, la aflicción que ella origina por su naturaleza e intensidad o por los efectos sociopersonales que desencadena, debe acomodarse a la importancia de la afección al objeto tutelado y la intensidad de la responsabilidad concurrente» ${ }^{64}$. Nuevamente aquí se constata el cariz ético de la discusión relativa al bien jurídico: «el Derecho penal, en virtud de los principios de ultima ratio del Derecho y del principio de proporcionalidad no puede ser el instrumento para proteger esos intereses estatales que se plasman en el control de los flujos migratorios» ${ }^{65}$. Sin embargo, los fines de la pena se prestan, en este discurso, a un mejor análisis en el siguiente peldaño analítico.

En el plano de la racionalidad teleológica se permite, en el discurso legislativo, el análisis de los concretos fines político-criminales que persiguen las normas jurídico-penales objeto de valoración: fines instrumentales de carácter preventivo-general o especial, fines simbólicos de corte preventivo-general positivo, etcétera. La originaria comprensión de ATIENZA, establecer «no si el Derecho persigue ciertos fines, sino si los fines que persigue son precisamente los que debería perseguir» ${ }^{66}$, puede asumirse más fácilmente en el análisis de un discurso jurídico de interpretación y/o aplicación del Derecho $^{67}$. Pues aquí la finalidad no se infiere de las normas instrumentales, o de la concreta exposición de motivos, ni cabe riesgo de disociación entre uno y otro tipo de contenidos normativos, sino de la funcionalidad de las concretas soluciones jurídicas. Se trata, en este plano, de valorar si la concreta comprensión del bien jurídico protegido permite castigar, únicamente, aquellas conductas a las que subyace una «consideración de las personas como mercancía», favoreciendo así una comprensión de este precepto como «interdicción del trato vejatorio que representa convertir en cosas a los

${ }^{62}$ Sugiriendo su desplazamiento «al nivel ético-político de la racionalidad teleológica», J. DíEZ, cit., n. ${ }^{\circ} 18$, p. 147.

${ }^{63}$ J. DíEZ, cit., n. ${ }^{\circ} 18$, p. 158.

${ }^{64} \mathrm{~J}$. DízZ, cit., n. ${ }^{\circ} 18$, p. 162 . En relación con este último, en la doctrina de nuestro Tribunal Constitucional, ilustrativo S. MIR, cit., n. ${ }^{\circ}$ 58, pp. 354 y ss., quien relaciona este principio, p. 351, con «exigencias tradicionalmente vinculadas a la idea de justicia o retribución con la propia lógica de la utilidad de la protección jurídico-penal y con el respeto de las valoraciones sociales».

${ }^{65}$ B. GARCÍAcit., n. ${ }^{\circ} 1$, p. 850 , cursiva añadida; igualmente vid. pp. 851 y ss.

${ }^{66}$ M. ATIENZA, cit., n. ${ }^{\circ} 18$, p. 39.

${ }^{67}$ En relación con el discurso legislativo, críticamente también J. DíEZ, cit., n. ${ }^{\circ} 50$, p. 283 y ss.; ID., cit., n. ${ }^{\circ} 18$, pp. 94 y ss., para quien en este plano se deben «sentar las bases para un discurso ético-político en el que, presupuestos los principios anteriores, se produzca una confrontación racional entre contenidos éticos de segundo orden, es decir, carentes de una aceptación libre de cualquier desacuerdo en la colectividad, e intereses particulares y sectoriales muy diversos, procedentes todos ellos de agentes sociales y grupos de presión de amplio espectro». 
seres humanos» ${ }^{68}$, y por tanto, permite una concreción de los fines preventivos tendente a «los que debería perseguir». O, por el contrario, incurre en excesos defensivistas facilitando una utilización del «Derecho Penal para la represión de determinadas infracciones (administrativas) que afectan a la entrada y salida ilegal de extranjeros» ${ }^{69}$, por poner dos ejemplos. En este segundo nivel de racionalidad procede también entrar a valorar la ratio legis, si bien ahora en cuanto sustento de la concreta argumentación jurídica ${ }^{70}$. En este sentido, resulta ilustrativa la argumentación de GARCÍA SÁNCHEZ, quien sustenta su propuesta —entre otros aspectos- en una interpretación de la voluntas legislatoris a partir de la reforma operada por la LO 11/2003, así como en la ausencia de componentes de peligro o de resultado en la conformación del tipo básico del mentado art. 318 bis $^{71}$. En este punto, también es preciso advertir frente a posibles excesos. Pues principios éticos priorizan, en ese plano, una interpretación teleológica con contenidos aceptables en tales términos de racionalidad — por ejemplo, sobre razones de proporcionalidad o responsabilidad subjetiva - frente a interpretaciones deficientes sustentadas en mayor o menor medida, en una voluntad en igual medida - éticamente- deficiente del legislador orgánico. De ahí que no se entienda la frontal crítica de lege ferenda que opone esta última autora a su — propia- propuesta de comprensión del bien jurídico ${ }^{72}$; pues las mismas razones pesan igualmente en contra de su postura de lege lata. En cuanto a posibles indicadores de estos otros contenidos de racionalidad, se apuntan entre otros aspectos, los márgenes de lo punible - o de amplitud típica- y de rigor punitivo del concreto constructo o comprensión jurídica $^{73}$.

ATIENZA concreta la racionalidad pragmática, con carácter general, en el examen de su función directiva, esto es, en el grado de «adecuación de la conducta de los destinatarios a lo prescrito en la ley» ${ }^{74}$. En este plano no divergen en exceso los discursos legislativo y de interpretación y/o aplicación del Derecho, se trata en ambos casos del argumento consecuencialista general. En específicos términos jurídico-penales, el examen de racionalidad pragmática permite, igualmente, tanto una valoración de la idoneidad abstracta del concreto constructo en términos de comprensión y reducción de las formas de violencia relevante, así como, en términos concretos, de la aplicabilidad — técnica e instrumental — de tal solución jurídica. En este tercer peldaño, se trata también del objeto y ámbito de tutela o del grado de intensidad de la misma, si bien aquí no se pretende establecer su significado teleológico (orientación preventivo-general, especial, etc.) y constatar su adecuación desde las perspectivas ya apuntadas; sino que, simplemente, interesa su idoneidad para comprender el campo problemático jurídico-penalmente relevante. $\mathrm{El}$ análisis de la racionalidad pragmática exige aprehender la realidad

${ }^{68}$ C. Villacampa, 2004: cit., n. ${ }^{\circ}$ 5, p. 186.

${ }^{69}$ B. GARCÍA, cit., n. ${ }^{\circ}$ 1, p. 850.

${ }^{70}$ No obstante, con carácter general, J.-M. SILVA, 2007: «Zur sogenannten teleologischen Auslegung», en Festschrift für Günther Jakobs, Köln: Carl Heymanns, p. 657, advirtiendo al respecto que la interpretación teleológica es en realidad pensamiento dogmático, de lo que deduce solamente legitimación sistemática.

71 B. GARCÍA, cit., n. ${ }^{\circ} 1$, p. 850.

${ }^{72} C f r$. B. GarCía, cit., n. ${ }^{\circ} 1$, pp. 850 y ss.

${ }^{73}$ J. DíEZ, cit., n. ${ }^{\circ} 18$, p. 94.

${ }^{74}$ M. AtienzA, cit., n. ${ }^{\circ} 18$, pp. 36 y ss. En esta línea, también, sugiere J. DíEZ, cit., n. ${ }^{\circ} 18$, p. 95 , ajustar aquí «los objetivos trazados por la racionalidad teleológica a las posibilidades reales de intervención social que están al alcance de la correspondiente decisión legislativa». 
práctica de las normas ${ }^{75}$. Se apunta al respecto el protagonismo de factores económicos junto a los criterios normativos de eficacia. En relación con el problema que nos ocupa, cabe señalar la posibilidad de excesos, de forma que el concreto bien jurídico favorezca una extensión indeseable de lo punible y, con ello, la represión penal de conductas más bien propias «de determinadas infracciones (administrativas) que afectan a la entrada y salida ilegal de extranjeros» ${ }^{76}$. También los problemas de concreción del bien jurídico, y es que ¿cómo se determina lo punible —en relación con el art. 318 bis del Código Penal español - a partir de un bien jurídico como «la dignidad de la persona» en cuanto «máxima expresión de un sistema de derechos fundamentales dotado de unidad y de sentido»? ${ }^{77}$. Y ello aun cuando en términos de racionalidad ética y teleológica el concreto constructo merezca una valoración —en mayor o menor medida- positiva ${ }^{78}$.

En el nivel de racionalidad jurídico-formal se facilita un análisis del engranaje del constructo en el marco jurídico, y en particular, de su adecuación a la concreta estructura del precepto. Así, veíamos como RoDRíGUEZ MonTAÑÉs, sopesaba por una parte «la rúbrica del Título XV bis», Delitos contra los derechos de los ciudadanos extranjeros, y por otra, «la ubicación sistemática del precepto (entre los delitos contra los derechos de los trabajadores y los relativos a la ordenación del territorio y medio ambiente) $\gg^{79}$. Mientras que, en un sentido negativo, sostiene a favor de esta última línea, «que los derechos individuales de los inmigrantes (vida, libertad, integridad, dignidad) son tutelados directamente por los mismos preceptos penales que tutelan los derechos de los ciudadanos españoles, pues a los efectos de la protección penal no se establece ninguna diferenciación entre nacionales y extranjeros, en situación legal o ilegal» ${ }^{80}$. Por su parte, VILLACAMPA ESTIARTE advierte los costes de su postura en este plano, asumiendo que la ubicación sistemática del Título XV bis se «compadece mejor con la afirmación de la protección de un interés económico», frente a otro tipo de intereses y, en particular, con «la dignidad humana como base para el ejercicio del resto de derechos» ${ }^{81}$. En términos de racionalidad jurídico-formal, una proposición normativa puede calificarse como deficiente o irracional «si y en la medida en que la misma contribuye a erosionar la estructura del ordenamiento jurídico» ${ }^{82}$. El grado de corrección dogmática, esto es, de adecuación a un concreto pensamiento dogmático, puede igualmente analizarse en este plano, dado que las diversas posibilidades discursivas que ofrecen ciertos modelos (finalistas, kantianos, etc.) impiden la comprensión sin más, de una argumen-

${ }^{75}$ Con carácter general, R. ALEXY, cit., n. ${ }^{\circ} 23$, p. 200: «Hay que respetar los límites de realizabilidad realmente dados». En nuestra doctrina, J. DíEZ, cit., n. ${ }^{\circ} 18$, pp. 94 y ss.; ID., cit., n. ${ }^{\circ}$ 50, p. 284 y ss.; J. VogEL, cit., n. ${ }^{\circ} 54$, p. 268.

76 B. GARCÍA, cit., n. ${ }^{\circ} 1$, p. 850.

${ }_{77}$ Críticamente, con razón M. CANCIO y M. Maraver, cit., n. ${ }^{\circ} 2$, pp. 372 y ss.

${ }_{78}$ En este sentido, ilustrativo M. ATIENZA, cit., n. . 19, p. 203: «La noción clave en la concepción material de la argumentación es la de razón: las premisas son razones (buenas razones) que apoyan la conclusión; y si partimos de la distinción que acabamos de examinar entre razonamientos teóricos y prácticos, tendríamos dos tipos fundamentales de razones: razones para creer en algo y razones para actuar».

79 T. RODRÍGUEZ, cit., n. ${ }^{\circ}$ 10, p. 1738 . Críticamente, también vid. J. HORTAL, cit., n. ${ }^{\circ}$ 2, p. 485, para quien la ubicación sistemática del precepto no permite inferir un componente económico definidor. Igualmente, vid. F. DE LEÓN, cit., n. ${ }^{\circ}$ 5, p. 251, para quien este precepto «debiera haberse reconducido al Libro II, Título VII, De las torturas y otros delitos contra la integridad moral, o al menos entre los Títulos dedicados a la protección de bienes personalísimos».

${ }^{80}$ Ibídem.

${ }^{81}$ C. Villacampa, 2004: cit., n. ${ }^{\circ}$ 5, p. 186.

${ }^{82}$ M. ATIENZA, cit., n. ${ }^{\circ} 18$, p. 33. 
tación sistemática como ética, en cuanto razones de certeza o seguridad jurídica ${ }^{83}$; si bien este tipo de argumento se manifiesta, particularmente, en el discurso relativo a la parte general del Código Penal: ubicación del dolo, concepto material de culpabilidad, etc. ${ }^{84}$. En cuanto a la estructura del precepto, se trata de la adecuación de determinadas interpretaciones a la estructura adoptada por el legislador en la formulación del mismo: delito de resultado o de mera actividad, por poner dos ejemplos ${ }^{85}$. Así, concluye al respecto RODRÍGUEZ MONTAÑÉS: «nos encontramos ante un delito contra el orden socioeconómico (bien institucionalizado o espiritualizado, supraindividual y de carácter inmaterial), en que se tutela uno de los aspectos del mismo (el fenómeno migratorio), tutela que se lleva a cabo mediante la técnica de los delitos de peligro abstracto (ante la imposibilidad de tipificar la lesión o la concreta puesta en peligro) recurriendo a objetos o bienes intermedios (los derechos individuales de los inmigrantes como colectivo y el respeto de la regulación en esta materia) que tienen función representativa del bien institucionalizado o interés difuso» ${ }^{86}$. Se señala aquí, entre otros aspectos, la importancia de la teoría del Derecho y de la lógica jurídica ${ }^{87}$.

Por último, en la racionalidad lingüística puede analizarse el grado de adecuación al tenor literal ${ }^{88}$. En cuanto a su tratamiento en este último peldaño, particularmente, en el análisis de un discurso jurídico orientado no a la creación, sino a la interpretación y/o aplicación del Derecho, se explica porque hemos partido de lo discursivamente racional. De ahí que una vez dentro de los márgenes semánticos posibles, el peso de este tipo de argumento se decida, esencialmente, en los niveles de análisis anteriores ${ }^{89}$.

La disección del material dogmático en planos de racionalidad se intuye como una tarea ingente. Sin embargo, el desarrollo de una teoría de la argumentación jurídico-penal no se ajusta bien al afán enciclopédico y exhaustivo característico del pensamiento

${ }^{83}$ No obstante, apunta J.-M. SILVA, cit., n. ${ }^{\circ} 70$, p. 658, la «legitimación qua racionalidad, que dado el caso, le confiere el predicado de que se encuentra plenamente justificada en el marco del sistema dogmático». Igualmente, vid. J. HRusCHKA, 1981: cit., n. ${ }^{\circ}$ 42, pp. 239 y ss. En esta línea, también, N. MACCORMICK, cit., n. ${ }^{\circ}$ 30, p. 13: «El pensamiento racional, sea acerca de qué hacer o acerca de qué sea el caso, debe presentar cualidades de consistencia a lo largo del tiempo y de universalidad a lo largo de los casos, y debe, por consiguiente, ser sistemático»; igualmente, pp. 16 y ss.; J. WRÓBLEWSKI, cit., n. ${ }^{\circ} 39$, p. 43: «El conjunto al que pertenece la norma legal es un sistema jurídico y, por tanto, los caracteres de este sistema se consideran relevantes para el significado de aquélla»; deduciendo sobre las ideas de consistencia y coherencia, ult. cit., p. 49: «(DI'-8): A una regla legal se le debería atribuir un significado que le hiciera lo más coherente posible con otras reglas legales pertenecientes al sistema». Con carácter general, R. ALEXY, cit., n. ${ }^{\circ} 23$, p. 261: «(J. 12) Si son posibles argumentos dogmáticos, deben ser usados»; sobre las funciones de estabilización, progreso, descarga, técnica, control y heurística de la dogmática, pp. 255 y ss.

${ }^{84}$ Últimamente, señalando «en este sentido, el déficit sistemático de la parte especial [...], que aumenta en ella el riesgo de decisionismo», J.-M. SILVA, cit., n. ${ }^{\circ}$ 70, p. 661. Con carácter general, también J. HRUSCHKA, 1984: cit., n. ${ }^{\circ}$ 42, p. 9, señalando la importancia del componente intuitivo.

${ }^{85}$ En sede de tipicidad, si bien ello es extrapolable a las argumentaciones relativas a los distintos peldaños de la teoría jurídica del delito. Sobre la distinción apuntada vid. J. CEREZO, 1998: Curso de Derecho Penal espanol. Parte general II. Teoría jurídica del delito, 6. ${ }^{a}$ ed., Madrid: Tecnos, pp. 101 y ss., 111 y ss.

${ }^{86}$ T. RodríGUEZ, cit., n. ${ }^{\circ}$ 10, p. 1738. Críticamente, sin embargo, véase M. GARCíA, cit., n. ${ }^{\circ}$ 5, p. 374; J. HORTAL, cit., n. ${ }^{\circ}$ 2, pp. 484 y ss.; F. PÉREZ, cit., n. ${ }^{\circ}$ 37, p. 44.

${ }^{87}$ M. ATIENZA, cit., n. ${ }^{\circ} 18$, pp. 33 y ss.

${ }^{88}$ En este sentido, señala R. ALEXY, cit., n. ${ }^{\circ} 23$, p. 237, que las formas de la argumentación semántica se refieren a la vinculación de los órganos decisores con el tenor de la ley; y deduce su fuerza, mediata o inmediatamente, del principio de autoridad del Derecho positivo, hablando por ello de «argumentos institucionales», R. AlEXY, cit., n. ${ }^{\circ}$ 15, p. 121.

${ }_{89}$ En este sentido, adscribiendo a las razones institucionales sólo «una preeminencia prima facie», R. ALEXY, cit., n. ${ }^{\circ} 15$, p. 121. 
dogmático ${ }^{90}$. La perspectiva argumentativa se centra más bien en el desarrollo de un modelo procedimental que permita incrementar los márgenes de racionalidad de las concretas soluciones jurídicas ${ }^{91}$. Se trata, con otras palabras, de elaborar pautas valorativas o referenciales que favorezcan un incremento de los contenidos de racionalidad de nuestra argumentación y, en consecuencia, también, de nuestras soluciones. Ello incide, en un segundo plano, en una acentuación de la perspectiva problemática frente al sistema. Pues la comprensión argumentativa relativiza este otro tipo de razones, sistemáticas y las sitúa - junto a otros argumentos - en uno de los diversos planos de racionalidad. Luego, no se trata ya de reconducir — por principio - el problema a través de un sistema ${ }^{92}$, sino simplemente de comprender en la mejor medida posible las razones y contenidos de racionalidad relevantes en la decisión del bien jurídico protegido en el art. 318 bis o las relativas a la posibilidad de graduar a través de diversas formas de intervención delictiva, la responsabilidad de los sujetos garantes, por poner dos ejemplos. Todo ello empuja a una perspectiva tópica, en la que primen los márgenes de rendimiento — en términos de racionalidad - de las diversas propuestas de solución. Pero vayamos por partes. De momento, aquí, se puede avanzar una respuesta a la primera de las cuestiones planteadas: una argumentación de Derecho puede analizarse aquí en términos de racionalidad, esto es, desde una serie de perspectivas problemáticas que reflejen los diversos planos de racionalidad que debe satisfacer un operador jurídico en la formulación de sus soluciones.

\section{2. ¿Cómo evaluar una argumentación de Derecho?}

La distinción entre diversos planos de racionalidad facilita la evaluación de una concreta argumentación jurídico-penal. Con carácter general, cabe desgranarla según el carácter de las diversas razones aducidas —ético, teleológico, pragmático, jurídico-formal o lingüístico- y ponderar términos homogéneos en cada uno de estos peldaños. Incluso, en función de la entidad o cantidad de los materiales argüidos, es posible pensar en graduaciones. Por ejemplo, en un sentido próximo a ALEXY, asumiendo escalas triádicas y adscribir así un valor «leve», «medio» $\mathrm{y}$ «alto», según proceda, atendiendo a los diversos contenidos de racionalidad ${ }^{93}$. De este modo, volviendo a la discusión relativa al 318 bis del Código Penal español, cabría asignar a la argumentación de GARCÍA SÁNCHEZ un valor alto de racionalidad jurídico-formal, que se concreta principalmente en la evitación de «problemas prácticos a la hora de determinar el ámbito punitivo de la conducta del tipo básico, pues los derechos de los extranjeros (como se postula desde posiciones contrarias) [...], donde se protegen realmente es en los tipos agravados (por lo que no concibe) [...], una afección a los derechos de los extranjeros sin que concurra alguna de las circunstancias agravantes de los n. ${ }^{\circ 5} 2,3,4$ y 5 [...] Con lo que en la práctica se quedaría vacío de contenido el n. $^{\circ} 1$ del 318 bis» ${ }^{94}$. Igual-

${ }^{90}$ Si bien pretende ir más allá de la propuesta de R. ALEXY, cit., n. ${ }^{\circ} 23$, pp. 37 y ss., perfilando ulteriores parámetros de discriminación, dentro de lo racional.

${ }^{91}$ Ilustrativo J. GarCía AMADO, 1987: «Tópica, Derecho y método jurídico», Doxa, n. ${ }^{\circ}$ 4, pp. 177 y ss.

${ }_{22}$ Paradigmático, K. LARENZ, cit., n. ${ }^{\circ}$ 39, p. 156: «Un [...] problema sólo puede considerarse satisfactoriamente resuelto cuando la solución ha sido integrada en el sistema», apuntando, no obstante, que cuando «no puede ser resuelto en el marco del sistema conocido no debe, por ello, ser preterido, sino que requiere una modificación del sistema»; en estos últimos términos, igualmente véase p. 174.

${ }^{93}$ R. AleXY, cit., n. ${ }^{\circ} 43$, p. 33.

${ }_{94}$ B. GARCÍA, cit., n. ${ }^{\circ} 1$, p. 850. 
mente, la referencia a la voluntad del legislador a través de la reforma de la LO 11/2003 y la formulación del tipo básico ${ }^{95}$, son susceptibles de encuadrarse en las racionalidades teleológica y lingüística, si bien la acentuación de los excesos preventivos que favorece esta comprensión así como la oscuridad del precepto, desaconsejan otorgar más que un valor medio y leve, respectivamente. Luego, resultaría una argumentación —esto es, conjunto de premisas y conclusiones ordenados en formas como la expuesta ${ }^{96}$ — con «alto» valor jurídico-formal, un valor «medio» de racionalidad teleológica y contenidos leves de racionalidad lingüistica. Frente a ello, se infieren en la argumentación de VILLACAMPA ESTIARTE diversos contenidos éticos. En concreto, apunta razones de lesividad y proporcionalidad: «la búsqueda de un bien jurídico que dotara de un contexto material de antijuridicidad a la conducta típica y que impidiera su conversión en una mera infracción formal, evitando una interpretación del tipo que condujera a considerarlo como infracción administrativa elevada a la categoría de delito» ${ }^{97}$; así como de fragmentariedad: «evitar la infracción del principio de ultima ratio que podría suponer la incriminación de una conducta contra un indicador macroeconómico» ${ }^{98}$. Subsidiariamente, también, apunta la nomenclatura escogida para este Título XV bis, «Delitos contra los derechos de los ciudadanos extranjeros» ${ }^{99}$, si bien en sentido contrario, su ubicación en el Código, asumiendo un leve valor jurídico-formal ${ }^{100}$. De ello resulta, por tanto, una argumentación con alto valor ético y leve valor en este último plano jurídico-formal, mientras que la mayor adecuación de lo punible a lo «que se debería perseguir», permite asignar también, un valor leve de racionalidad teleológica.

Este tipo de comprensión facilita también una posible expresión —-metafóricanumérica, atribuyendo un significado en cifras a cada una de las tres valoraciones escogidas: «1», «2»y «3», por poner otro ejemplo. Ello permitiría ya esbozar un primer cuadro:

\begin{tabular}{lcc}
\hline & GARCÍA SÁNCHEZ & VillaCAMPA ESTIARTE \\
\hline Racionalidad ética & & 3,0 \\
Racionalidad teleológica & 2,0 & 1,0 \\
Racionalidad pragmática & & 1,0 \\
Racionalidad jurídico-formal & 3,0 & \\
Racionalidad lingüística & 1,0 & 5,0 \\
\hline \multicolumn{1}{c}{ Total } & 6,0 & \\
\hline
\end{tabular}

${ }_{95}$ Ibidem.

${ }^{9}$ Cfr. M. AtienzA, cit., n. ${ }^{\circ}$ 19, p. 75, definiendo la argumentación como «el conjunto de los enunciados (o quizá mejor, de las entidades) en las que cabe distinguir siempre tres elementos: las premisas (aquello de lo que se parte), la conclusión (aquello a lo que se llega) y la inferencia (la manera como están unidas las premisas y la conclusión, la relación que existe entre ambos tipos de entidades)».

${ }_{97}$ Adecuando así supuesto de hecho y consecuencia jurídica, C. VillaCAMPA, 2004: cit., n. ${ }^{\circ}$ 5, p. 186.

98 Particularmente, véase C. Villacampa, 2004: cit., n. ${ }^{\circ}$ 5, p. 187; ID., 2005: cit., n. ${ }^{\circ}$ 5, p. 1666.

99 Así también F. MuÑOZ, 2007: Derecho penal. Parte especial, 16. ${ }^{a}$ ed., Valencia: Tirant lo blanch, p. 355.

${ }^{100}$ C. VillaCAmPA, 2004: cit., n. ${ }^{\circ}$ 5, p. 186; ID., 2005: cit., n. ${ }^{\circ}$ 5, p. 1667 . Insistiendo en el primer aspecto, frente a la anterior postura, M. GARCÍA, cit., n. ${ }^{\circ}$ 5, p. 373: «La referencia a dichos intereses de carácter estatal resulta difícil de mantener como bienes jurídicos protegidos en los tipos de tráfico ilegal de personas, claramente basados en la protección de los derechos de éstas, incluso en las rúbricas que los acogen». Anteriormente, también M. RODRÍGUEZ, cit., n. ${ }^{\circ} 8$, p. 55. 
En esta misma línea, la diversa significación de las distintas racionalidades se presta también a una expresión en estos términos. Antes aludíamos a la primacía de la racionalidad ética sobre las restantes racionalidades. Luego, si se entiende que las mismas siguen un orden decreciente, pudiera convenirse en una correlativa multiplicación de los distintos valores de racionalidad que reflejasen — de alguna u otra forma- el distinto peso de unos y otros contenidos. Por poner nuevamente un ejemplo, multiplicar el valor de racionalidad ética por «2», teleológica por «1,75», pragmática por «1,5», jurídico-formal por «1,25» y lingüística, finalmente, por «1». Con otras palabras:

\begin{tabular}{lcc}
\hline & GARCÍA SÁNCHEZ & VILLACAMPA ESTIARTE \\
\hline $\begin{array}{l}\text { Racionalidad ética } \\
\text { Racionalidad teleológica }\end{array}$ & $2(\cdot 1,75)$ & $3(\cdot 2)$ \\
$\begin{array}{l}\text { Racionalidad pragmática } \\
\text { Racionalidad jurídico-formal }\end{array}$ & $3(\cdot 1,25)$ & $1(\cdot 1,75)$ \\
Racionalidad lingüística & $1(\cdot 1)$ & $1(\cdot 1,25)$ \\
\hline \multicolumn{1}{c}{ Total } & 8,25 & \\
\hline
\end{tabular}

Salvo la acentuación del nivel ético ${ }^{101}$, muchos de cuyos valores gozan en nuestro marco positivo de rango constitucional, la asignación de un factor multiplicador al resto de racionalidades suscita serias dudas. Por poner un ejemplo: ¿Cabe una priorización —así, con carácter general— de las razones pragmáticas frente a las jurídico-formales? De hecho, el peso que ostenta la idea de sistema en nuestro pensamiento jurídico apunta más bien en un sentido contrario ${ }^{102}$. Con carácter general, apunta ATIENZA que «la atribución de peso depende de que, en última instancia, se asuma una concepción formalista, deontologicista o consecuencialista, y que cada cultura jurídica puede mostrar una mayor inclinación hacia alguna de esas tres concepciones» ${ }^{103}$. En relación con nuestro discurso, cabe señalar el carácter instrumental de la norma -frente al problema- y ello particularmente, una vez dentro de los márgenes de racionalidad ética y de lo discursivamente posible. Este último aspecto, apunta también a la subordinación de la racionalidad lingüística, y del carácter extensivo o restrictivo de una interpretación,

101 Y más allá del concreto valor asignado: $(\cdot 2),(\cdot 3)$ o (.5). Con carácter general, señalando la importancia de los argumentos de principio en «los Estados constitucionales democráticos», R. ALEXY, cit., n. ${ }^{\circ}$ 15, p. 120.

102 En este sentido, veíamos, apuntaba R. AlEXY, cit., n. ${ }^{\circ} 23$, p. 239, que «(J. 8) la determinación del peso de los argumentos de distintas formas debe tener lugar según las reglas de la ponderación», y que «tales reglas sólo pueden desarrollarse con referencia a determinados contextos de interpretación y determinados sectores del Derecho». Igualmente M. AtIENZA, cit., n. ${ }^{\circ}$ 19, p. 228: «la relevancia de las razones, de las premisas, provenientes del sistema jurídico están en función de su aplicabilidad, interpretación y validez».

103 Señalando, «en definitiva, en el funcionamiento de nuestros sistemas jurídicos no se puede partir de una jerarquización estricta de las razones: no es cierto que las razones de corrección prevalezcan siempre sobre las finalistas, y unas y otras sobre las autoritativas. Sí que cabe hablar, sin embargo, de una jerarquía débil, derrotable: las razones de corrección gozan de prioridad prima facie, pero pueden ser derrotadas por razones de fin (por objetivos sociales) en ciertas circunstancias excepcionales, y unas y otras (las razones sustantivas) pueden ser derrotadas también por razones institucionales», M. ATIENZA, cit., n. ${ }^{\circ} 19$, p. 235; igualmente, op. cit., p. 242; sobre la relatividad de la distinción entre razones institucionales y sustantivas, véanse pp. 240 y ss.; sobre la noción de falacia y una posible clasificación, también véase p. 279. 
por encima de aspectos semánticos, a las razones precedentes ${ }^{104}$. Pero sobre éstas y otras cuestiones se deberá entrar en otro lugar.

De momento, aquí, basta señalar tres aspectos. Primero, es preciso advertir de las distintas falacias y, en particular, de las peticiones de principios, esto es, cuando se postula, sin más, aquello que se pretende probar; sea una propuesta de bien jurídico o cualquier otro tipo de conclusión. En tales casos, una argumentación que se agota en insistir en la conclusión, sin referencia a premisas o contenidos de racionalidad sobre los que se sustente o infiera la misma, muestra -lógicamente, en tales términos y en cuanto argumentación - valor 0 . En segundo lugar, y aunque aquí nos ocupemos del discurso de interpretación y aplicación del Derecho, la distinción entre diferentes parámetros de racionalidad y su posible gradación, se muestra particularmente fructífera en la comparación de textos normativos, y en general, en el discurso legislativo, donde a la discriminación entre diversas perspectivas de enjuiciamiento se suma la posibilidad de confrontar, no ya argumentos de diverso corte, sino cuerpos normativos con un importante grado de homogeneidad. En este sentido, el pronóstico expresado en relación con el —entonces-Anteproyecto de reforma de la ley penal del menor: «el Anteproyecto perfilado por el gobierno conlleva un importante coste de racionalidad ética — se agotan los principios de humanidad de las penas, proporcionalidad y culpabilidad, se subordina el interés del menor para responder a un discurso de importante contenido emocional - sin que quede claro el resultado a corto plazo que puede aportar la misma. A largo plazo, la política criminal instrumentada suele mostrarse desafortunada. El hecho de que se trate del sector de delincuencia donde mayor sentido cobran las ideas de reeducación y reinserción social, la existencia de vías alternativas en el Derecho comparado o los importantes costes en términos teleológicos y sistemáticos» ${ }^{105}$; se presta a una fácil representación en estos términos:

\begin{tabular}{lll}
\hline & LO 5/2000 & Anteproyecto \\
\hline Racionalidad ética & $2(\cdot 2)$ & \\
Racionalidad teleológica & $1(\cdot 1,75)$ & \\
Racionalidad pragmática & $1(\cdot 1,50)$ & $1(\cdot 1,50)$ \\
Racionalidad jurídico-formal & $1(\cdot 1,25)$ & $1(\cdot 1,25)$ \\
Racionalidad lingüística & $1(\cdot 1)$ & $1(\cdot 1)$ \\
\hline \multicolumn{1}{c}{ Total } & 9,50 & 3,75 \\
\hline
\end{tabular}

104 Con carácter general, J. WRÓBLEWSKI, cit., n. ${ }^{\circ}$ 39, p. 54, «(DI²-16): Cuando se da una diferencia entre el significado funcional SF de una regla legal y su significado lingüístico SL (y/o su significado sistémico), prevalece el primero». Igualmente, ilustrativo K. LARENZ, cit., n. ${ }^{\circ} 39$, pp. 320 y ss., 341: «El sentido literal inferible [...] sirve a la interpretación, en primer lugar, como primera orientación; en segundo lugar señala, en cuanto posible sentido literal [...] el límite de la interpretación propiamente dicha». En relación con este último aspecto, no obstante, apuntando cierta inconsecuencia J.-M. SILVA, cit., n. ${ }^{\circ}$ 70, p. 647: «La gran mayoría de la doctrina penal se pronuncia teóricamente en contra de rebasar los márgenes del sentido usual de las palabras - por limitado que sea- por razones teleológicas. Sin embargo, no es raro que estos mismos autores asuman tales excesos en su actividad dogmática»; cuestionando la comprensión de este proceder como interpretación («Auslegung»), p. 652; en relación con sus límites, pp. 658 y ss.

105 F. SÁNCHEZ, cit., n. ${ }^{\circ}$ 49, p. 202; también véase ID., 2007: «Zur neuesten Reform des spanischen Jugendstrafrechts», ZIS, n. ${ }^{\circ} 2$, pp. 63 y ss. 
$\mathrm{Y}$ cabe pensar en representaciones negativas, pues aun cuando la anterior formulación de la LO 5/2000 mostrase, en relación con el citado Anteproyecto de reforma, un nivel de racionalidad medio, esta valoración no se adecua a los distintos excesos de aquel texto normativo. En cualquier caso, este tipo de representaciones no son más que ilustrativas o metafóricas. Porque, en tercer lugar, aquí somos de letras, y por encima de cifras o símbolos que nos sugieren —al menos de momento y— en primer lugar, resultados deportivos u otro tipo de representaciones. El modelo expuesto permite visualizar las carencias argumentativas de una y otra postura y, por ejemplo, argüir que GARCÍA SÁNCHEZ descuida en sus plantemientos los niveles de racionalidad ética y pragmática, o que VILLACAMPA EsTiARTE agota sus razones, básicamente, en el primero; y sobre ello, con los distintos matices e importancia que se conceda a los distintos contenidos, evaluar una u otra argumentación ${ }^{106}$.

\section{3. ¿Cómo argumentar en este sector del Derecho?}

Sentado lo anterior, la última de las cuestiones planteadas muestra una resistencia «leve» desde la perspectiva expuesta ${ }^{107}$. Así, sabemos que «argumentar es siempre una acción relativa a un lenguaje», y se diferencia de otros usos del lenguaje porque «su sentido (el sentido del conjunto) es el de sostener (refutar, modificar, etc.) una tesis, una pretensión, dando razones para ello» ${ }^{108}$, aquí hemos visto algunos ejemplos en relación con el bien jurídico protegido en el art. 318 bis del Código Penal español. Se trata, por tanto, de dar razones a favor o en contra de una determinada tesis ${ }^{109}$. Asimismo, se le adscribe carácter referencial: «presupone siempre un problema, una cuestión» ${ }^{110}$. En la argumentación jurídica, ello se concreta en un problema jurídico como, por ejemplo, la determinación del objeto de tutela por el mentado precepto. Y finalmente, se trata de una actividad racional «no sólo en el sentido de que es una actividad dirigida a un fin, sino en el de que siempre hay criterios para evaluar su argumentación, siempre parece tener sentido preguntarse si un argumento es bueno o malo, aparentemente bueno pero en realidad malo, mejor o peor que otro, etc. ${ }^{111}$. Pues bien, según esto, argumentar en el Derecho (penal) consiste en ofrecer razones significativas a favor o en contra de una solución jurídica, y más concretamente, significativas en los diversos planos problemáticos —o de racionalidad- que sujetan al operador jurídico, sea el juez, el legislador o el profesor de Derecho, en la elabora-

106 Se trata, por tanto, en palabras de J. WRÓBLEWSKI, cit., n. ${ }^{\circ}$ 39, p. 37, de un modelo teórico de interpretación operativa, esto es, que «señala los problemas a solventar por quien toma la decisión, pero no es la descripción de un proceso interpretativo». Sobre esto último vid. M. ATIENZA, cit., n. ${ }^{\circ} 23$, pp. 240 y ss., donde esboza un sugerente modelo para reconstruir los diversos procesos de argumentación. Sobre las acepciones descriptiva y normativa de la interpretación, ilustrativo J. WRÓBLEWSKI, cit., n. ${ }^{\circ}$ 39, pp. 69 y ss.

${ }_{107}$ Pues ciertamente, la preocupación mostrada se centra en la justificación de la aserción normativa, más que en su aplicación, y se descuidan igualmente criterios de racionalidad estratégica e instrumental; $c f r$. M. ATIENZA, cit., n. ${ }^{\circ}$ 23, pp. 226 y ss., 228 y ss., 237. Igualmente, ilustrativo ID., 2006: «Diez consejos para argumentar bien o decálogo del buen argumentador», Doxa, n. ${ }^{\circ} 29$, pp. 474 y ss.

${ }^{108}$ M. ATIENZA, cit., n. ${ }^{\circ}$ 19, p. 73. En palabras de K. LARENZ, cit., n. ${ }^{\circ}$ 39, p. 507: «Indicar las razones que permiten que una afirmación aparezca justificada, acertada o, al menos, discutible».

${ }^{109}$ Ibídem.

${ }^{110}$ M. AtIENZA, cit., n. ${ }^{\circ} 19$, p. 74.

111 M. AtienZA, cit., n. ${ }^{\circ}$ 19, p. 76. 
ción de sus distintas soluciones ${ }^{112}$; planos que, como se ha visto, permiten igualmente su evaluación.

\section{4. ¿QUÉ BIEN JURÍDICO PROTEGE EL ART. 318 BIS DEL CÓDIGO PENAL ESPAÑOL?}

Según lo visto hasta ahora, la adopción de una u otra solución —a un problema jurídico - se convierte en una cuestión de racionalidad, esto es, de márgenes de racionalidad argumentativa. Se trata de ponderar los diversos contenidos éticos, teleológicos, pragmáticos, jurídico-formales y lingüísticos presentes en unas y otras comprensiones. De este modo, el principio del mejor argumento adquiere ciertos tintes objetivos presentándose como una cuestión de eficiencia argumentativa en los señalados términos de racionalidad. Sobre ello cabe dilucidar, por ejemplo, qué bien jurídico protege el citado art. 318 bis del Código Penal español.

El actual estado de la cuestión ofrece tres grandes posicionamientos doctrinales ${ }^{113}$. Primeramente, quienes sugieren — por lo general, de forma particularmente crítica en términos de lege ferenda - que el bien jurídico protegido en este precepto es el control estatal de los flujos migratorios ${ }^{114}$. En segundo lugar, quienes interpretan el bien jurídico protegido sobre «la necesidad de acabar con cualquier tipo de explotación que afecte de una u otra forma a la entidad humana en sus rasgos constitutivos esenciales, en los términos descritos y que de forma genérica sintetizamos en el concepto de [...] integridad moral» ${ }^{115}$; postura que engarza, en último término, con la noción de «dignidad de la persona, configurada como el primero de los fundamentos del orden político y de la paz social (STC 113/1989 y 214/1991)» ${ }^{116}$. Y por último, quienes proponen un bien jurídico en buena medida coincidente con el Título donde se encuentra ubicado este precepto, esto es, derechos y libertades, y en definitiva, la esfera jurídica de los ciudadanos extranjeros. En esta última línea, nos hemos pronunciado anteriormente ${ }^{117}$.

En un reciente trabajo, concluye HORTAL IBARRA lo siguiente: «De hecho, y mucho a mi pesar [...], en los delitos contra los derechos de los ciudadanos extranjeros se protege directa y esencialmente la política estatal en el control de los flujos migratorios como uno de los ejes de la política económico-social nacional y uno de los pilares de la política comunitaria en materia de seguridad y control supranacional de las fronteras» ${ }^{118}$.

${ }_{112}$ En un sentido próximo, J. WRÓBLEWSKI, cit., n. ${ }^{\circ}$ 39, p. 62: «La idea fundamental es que una decisión interpretativa justificada debería identificar todos los argumentos determinados por los problemas básicos que tendrían que resolverse si la decisión fuera racional».

113 Sin perjuicio de ulteriores matizaciones derivadas de la compleja estructura del precepto; sobre todo ello, con amplias referencias bibliográficas, véase J. HORTAL, cit., n. ${ }^{\circ} 2$, pp. 463 y ss. Un interesante tratamiento histórico ofrece, igualmente J. LACRUZ, cit., n. ${ }^{\circ} 2$, pp. 2 y ss. En términos de política criminal, J. TERRADILLOS, 2006: «Extranjería, inmigración y sistema penal», en Inmigración y sistema penal, Valencia: Tirant lo blanch, pp. 39 y ss., particularmente, 51 y ss.

114 Últimamente, véase J. HORTAL, cit., n. ${ }^{\circ}$ 2, pp. 463 y ss., 481 y ss. Recientemente, también J. LACRUZ, cit., n. ${ }^{\circ}$ 2, p. 15.

15 F. DE LEÓN, cit., n. ${ }^{\circ}$ 5, p. 250.

116 F. DE LEÓN, cit., n. ${ }^{\circ} 5$, p. 249.

117 F. SÁNCHEZ, cit., n. ${ }^{\circ} 22$, p. 289.

118 J. HorTAL, cit., n. ${ }^{\circ}$ 2, pp. 481 y ss. En esta línea también M. AlOnSO, cit., n. o 2, pp. 16 y ss., quien no obstante adscribe cierta independencia al número segundo de este precepto, esto es, cuando «el propósito del tráfico ilegal o la inmigración clandestina fuera la explotación sexual de las personas», lo que se concreta, como 
Este autor desarrolla un importante aparato crítico mediante el que -negativamente, esto es, a través de una exposición crítica de las posiciones contrarias, erróneasva abriendo paso a su postura. En cuanto al sustento de ésta, apunta fundamentalmente a la estructura del precepto: razones jurídico-formales ${ }^{119}$. Señala al respecto, que «el principal cometido de la doctrina científica es interpretar los tipos de acuerdo con una serie de criterios por todos conocidos, detectar y "denunciar" las posibles incoherencias y/o incorrecciones técnicas en las que hubiera incurrido el legislador al incriminar un comportamiento y formular en todo caso las correspondientes propuestas de lege ferenda, pero no, en modo alguno [...], enmendarle la plana al legislador proponiendo interpretaciones que garantizan la aplicación del precepto en cuestión y dotan de cierta "coherencia" a una regulación carente de ésta» ${ }^{120}$. Como vemos, la argumentación de HORTAL IBARRA va más allá del problema del bien jurídico, y alcanza a esbozar unos límites a la labor hermenéutica. Frente a ello cabe oponer, de momento, que las interpretaciones que apuntan a bienes como la dignidad o la integridad moral, confiriendo así otros márgenes de operatividad y coherencia al precepto, no pretenden «enmendar la plana al legislador», sino a su interpretación de lo que constituye la misma ${ }^{121}$; y ello dando cuenta — con mayor o menor fortuna- de que sus pronunciamientos tienen lugar en un marco jurídico informado entre otras razones, por la de proporcionalidad, con la que engarzan principios como los de fragmentariedad, subsidiariedad y demás mencionados —en otro sentido- por este penalista $^{122}$. Pero vayamos por partes.

bien jurídico, en «la dignidad de la persona en cuanto tal, o si se prefiere la integridad moral, y no la llamada dignidad del colectivo de los ciudadanos extranjeros, lo que [...] se erige en elemento rector del tipo y es objeto de tutela jurídico penal»; J. LACRUZ, cit., n. ${ }^{\circ} 2$, pp. 29 y ss. De otra opinión STS 1465/2005, de 22 de noviembre, fundamento de derecho séptimo.

119 J. HORTAL, cit., n. ${ }^{\circ} 2$ 2, p. 501; insistiendo igualmente, op. cit., p. 475, en que «el bien jurídico-penal en un concreto delito no puede hacerse a espaldas del texto legal, porque de lo contrario se corre el riesgo de deferender una posición que resulta contraria a lo descrito en la propia conducta típica». En términos próximos, igualmente véase M. ALONSO, cit., n. ${ }^{\circ}$ 2, p. 16.

${ }^{120} \mathrm{~J}$. HORTAL, cit., n. ${ }^{\circ}$ 2, p. 482. En esta línea también, apuntan M. CANCIO y M. MARAVER, cit., n. ${ }^{\circ}$ 2, p. 375 , que «es preferible criticar abiertamente el precepto o, incluso, cuestionar su constitucionalidad antes que ignorar directamente lo establecido por el legislador». Con carácter general, K. LARENZ, cit., n. ${ }^{\circ}$ 39, p. 314: «La interpretación no debe ir más allá de la intención reguladora cognoscible y de las decisiones valorativas subyacentes a la regulación legal»; e igualmente, p. 342: «Siempre que el posible sentido literal y la conexión de significado de la ley dejen margen a diferentes interpretaciones, se ha de preferir aquella interpretación que mejor se ajuste a la intención reguladora del legislador y al fin de la norma respectiva». En relación con el argumento democrático, igualmente véase J. RAZ, cit., n. ${ }^{\circ} 21$, pp. 208 y ss., sobre la determinación de la intención, pp. 214 y ss.; señalando en cualquier caso, p. 233, que «en la práctica de la aplicación del derecho, la interpretación desempeña un papel aun donde la doctrina de la autoridad no alcanza, y donde la interpretación conservante es o bien imposible o injustificada».

${ }^{121}$ Ilustrativo J.-M. SILVA, cit., n. ${ }^{\circ} 70$, pp. 647 y ss., con ulteriores referencias en n. ${ }^{\circ} 16$; concluyendo, op. cit., p. 653, «que el bien jurídico es más un producto "teórico" que algo deducido de la ley»; igualmente vid. pp. 653 y ss.

${ }^{122}$ Cfr. J. HORTAL, cit., n. ${ }^{\circ}$ 2, p. 493 . Sobre el principio de proporcionalidad, ilustrativo S. Mir, cit., n. ${ }^{\circ} 58$, pp. 350 y ss., p. 352: «En realidad, el principio de proporcionalidad no sólo va más allá de la hipotética necesidad de un castigo justo del delito, sino también del propio Derecho penal, puesto que constituye un principio constitucional que impide al Estado imponer al ciudadano sacrificios desproporcionados»; en relación con el control de constitucionalidad, pp. 365 y ss. Recientemente, también J.-M. SILVA, cit., n. ${ }^{\circ}$ 70, pp. 652 y ss., señalando que «los tipos penales no se orientan a una protección integral del conceto "bien jurídico", sino únicamente, a su protección fragmentaria y subsidiaria». Con carácter general, R. ALEXY, cit., n. ${ }^{\circ} 23$, p. 239: «(J. 7) Los argumentos que expresen una vinculación al tenor literal de la ley o a la voluntad del legislador histórico prevalecen sobre otros argumentos, a no ser que puedan aducirse motivos racionales que concedan prioridad a los 
El agotamiento del discurso en el plano de racionalidad jurídico-formal —básicamente, estructura típica- tampoco se corresponde aquí con una valoración alta en tales términos. En este sentido, la concepción del bien jurídico apuntada no vierte claridad en la distinción de los márgenes correspondientes al art. 318 bis del Código Penal y al ilícito administrativo previsto en el art. 54.1.b) de la Ley Orgánica 4/2000 en su formulación actual ${ }^{123}$. Al contrario, acentúa costes sistemáticos. Así, concluye este penalista que «administrativamente se sancionan comportamientos más graves que los castigados en el ámbito penal al incluirse en la infracción de extranjería dos elementos (el ánimo de lucro y la realización de la conducta en el marco de una organización) que en el mencionado delito se configuran como circunstancias agravantes (arts. 318 bis 3 y [... 5 respectivamente), invirtiendo de esta forma los principios generales que sirven de base para establecer las fronteras entre los dos instrumentos que conforman el denominado ius puniendi del Estado» ${ }^{124}$. Tampoco, como reconocen CANCIO MELIÁ y MARAVER GÓMEZ, facilitan una distinción (des)valorativa entre la conducta del inmigrante y la del sujeto activo que la favorece ${ }^{125}$. Pues se apunta con razón, que «el inmigrante es sujeto activo de la entrada ilegal y con ello, infringe las normas administrativas que protegen el control de fronteras» ${ }^{126}$, luego la norma jurídico-penal que adscribe al inmigrante ilegal el papel de «víctima del favorecimiento del tráfico, no puede estar protegiendo la política migratoria porque ése es el interés de las normas administrativas que el inmigrante infringe» ${ }^{127}$. Entiendo que éstos y otros inconvenientes pudieran facilitarse a través de una comprensión del bien jurídico que atendiera, entre otras razones, a principios generales como los citados, y favorecer así una redistribución de lo punible sobre otro tipo de criterios —en definitiva, de proporcionalidad- más allá de compleja estructura típica que muestra este precepto ${ }^{128}$. HORTAL IBARRA ofrece, en de-

otros argumentos» (la cursiva es mía). No obstante, al respecto, también K. LARENZ, cit., n. ${ }^{\circ}$ 39, p. 343: «El juez que interpreta ha de prestar atención, en la concreción de los principios constitucionales, al primado de concreción del legislador. Si el principio permite varias concreciones, está vinculado a la elegida por el legislador, con tal de que ésta resida aún en el marco del margen de libre concreción limitado al legislador»; J. RAZ, cit., n. ${ }^{\circ} 21$, pp. 206 y ss.

${ }_{123}$ Cit., n. ${ }^{\circ} 37$.

${ }^{124}$ Cfr. J. HoRTAL, cit., n. ${ }^{\circ} 2$, pp. 498 y, anteriormente, también, p. 483, deduciendo la inaplicación del ilícito administrativo sobre «la preferencia del orden penal sobre el administrativo sancionador», $c f r$. pp. 499 y ss. En este último sentido M. CANCIO y M. MARAVER, cit., n. ${ }^{\circ}$ 2, pp. 366 y ss., concluyendo que el ilícito administrativo «no tiene ninguna posibilidad de ser aplicado»; igualmente vid. p. 380. En un sentido próximo, asumiendo costes en estos términos J. LACRUZ, cit., n. ${ }^{\circ} 2$, pp. 28 y ss.

${ }^{125}$ «Piénsese, por ejemplo, en el caso en el que alguien intenta cruzar la frontera con una persona que no está autorizada para ello. La amenaza contra el bien jurídico vendría producida por ambos sujetos», M. CANCIO y M. MARAVER, cit., n. ${ }^{\circ} 2$, p. 380.

${ }_{126}$ M. GARCÍA, cit., n. ${ }^{\circ}$ 5, p. 370 . En esta línea, ya E. GARCía y J. RodríGUEZ, cit., n. ${ }^{\circ}$ 10, p. 732 : «Los propios extranjeros víctimas de este delito serían a su vez autores, al infringir la prohibición legal de entrar en el país de forma clandestina o irregular». Recientemente, también A. PÉREZ, 2006: cit., n. ${ }^{\circ}$ 5, p. 117.

${ }_{127}$ M. GARCía, 2004: «Título XV bis. Delitos contra los derechos de los ciudadanos extranjeros», en J. CóRdoba y M. GarCía (dirs.), Comentarios al Código penal. Parte especial I, Madrid-Barcelona: Marcial Pons, p. 1325.

${ }^{128}$ En sentido contrario, sin embargo, J. HoRTAL, cit., n. ${ }^{\circ} 2$, p. 499. Críticamente, a su vez, STS 1087/2006, de 10 de noviembre, fundamento de derecho primero, infiriendo de la normativa internacional «una mens legis orientada hacia un plano supranacional de protección, a modo de interés difuso articulado no sólo para el mantenimiento del orden socioeconómico, sino especialmente dirigido al cuidado y respeto de los derechos de los extranjeros y de su dignidad en tanto seres humanos, evitando a través de tal delito de peligro abstracto que sean tratados como objetos, clandestina y lucrativamente, con clara lesión de su integridad moral. No se trata, pues, de una mera protección penal del interés público en someter a control administrativo el citado y cada vez 
finitiva, una argumentación con un moderado valor jurídico-formal, pero con importantes carencias éticas, teleológicas y pragmáticas; básicamente: se desatienden razones de lesividad, fragmentariedad y proporcionalidad en sentido estricto ${ }^{129}$; se favorece una consecución de fines preventivos bien distintos de «los que debería perseguir», esto es, la instrumentación del Derecho penal en la represión de actuaciones carentes de merecimiento y necesidad de pena ${ }^{130}$; lo que en términos pragmáticos, se traduce en una extensión inadecuada de lo punible. Con otras palabras, la actual doctrina mayoritaria sugiere una interpretación extensiva sobre un iter argumentativo con importantes deficiencias. Desde una perspectiva metodológica, a esta acentuación del plano jurídico-formal, subyace una subestimación de la dogmática en cuanto «proceso racional y conformador del Derecho» ${ }^{131}$.

En un sentido distinto, propone DE LEÓN VILLALBA la «integridad moral, como bien jurídico protegido por cualquier norma que regule el tráfico de personas» ${ }^{132}$. Seguidamente, identifica este interés con la «inviolabilidad de la libertad» ${ }^{133}$, y entronca así con la idea de dignidad, en la medida en que ésta «se manifiesta singularmente en la autodeterminación consciente y responsable de la propia vida y [...] lleva consigo la pretensión al respeto por parte de los demás» ${ }^{134}$. En cuanto al sustento de su postura, este penalista cede -igualmente- gran importancia a razones sistemáticas, y se apoya en instrumentos internacionales de derechos humanos, así como - particularmente, también - en los arts. 10.2 y 15 de la Constitución española ${ }^{135}$. En un segundo plano, sobre la conducta tipificada, entiende que «el tráfico de personas, en el marco de la explotación, constituye el ejemplo paradigmático de un trato inhumano, degradante que afecta profundamente a la personalidad, vejatorio, pero sobre todo que convierte al ser humano en un objeto más de comercio, con una voluntad invalidada y a expensas de la disposición que el traficante quiera hacer del mismo» ${ }^{136}$. Y sobre ello, deduce «que la tipificación y persecución de la conducta básica de tráfico se debe asentar directamente sobre la necesidad de acabar con cualquier tipo de explotación que afecte de una u otra forma a la entidad humana en sus

más frecuente flujo migratorio, cuya cirminalización quebrantaría así el principio de intervención mínima del Derecho penal».

${ }^{129}$ Cfr. STS 1465/2005, de 22 de noviembre, fundamento de derecho séptimo.

${ }_{130}$ Asumiendo «la incriminación de los actos de colaboración altruistas y/o humanitarios dada su posible subsunción en el tipo básico», J. HORTAL, cit., n. ${ }^{\circ} 2$ 2, pp. 494 y en términos similares, 491-493.

${ }^{131}$ M. ATIENZA, cit., n. ${ }^{\circ}$ 19, p. 54. En nuestra doctrina, ilustrativo G. RoDRíGUEZ, cit., n. ${ }^{\circ}$ 39, pp. 46 y ss., 47: «¿Quién no tiene noticia de que en determinado caso algún Tribunal, por razonables exigencias de equidad, abrió en su declaración de hechos probados puertas que estaban cerradas o derribó con su silencio muros o vallas que estaban erguidos para poder calificar los hechos como hurto y evitar la pena más grave del robo?». Igualmente R. AlEXY, cit., n. ${ }^{\circ} 23$, p. 220: «En los casos más complicados se necesita, para la fundamentación de las decisiones jurídicas, una serie de premisas [...] que no pueden ser deducidas de ninguna ley». Señalando la relación entre las «ideas acerca de la interpretación apropiada y el papel de una determinada intención (del legislador histórico, contemporáneo o del interprete) en la atribución de significado» a las diversas razones, también véase J. WRÓBLEWSKI, cit., n. ${ }^{\circ} 39$, p. 51.

${ }^{132}$ F. DE LEÓN, cit., n. ${ }^{\circ} 5$, p. 247, matizando que tal comprensión precisa «en algunos supuestos (violencia) de un complemento añadido que deriva del desarrollo concreto de la acción». Siguiendo al anterior, M. García, cit., n. ${ }^{\circ}$ 127, p. 1327; A. PÉREZ, 2006: cit., n. ${ }^{\circ} 5$, pp. 120 y ss.; F. PéreZ, cit., n. ${ }^{\circ} 37$, pp. 49 y ss.

${ }^{133}$ F. DE LEÓN, cit., n. ${ }^{\circ} 5$, pp. 248 y ss.

${ }^{134}$ F. DE LeÓN, cit., n. ${ }^{\circ}$ 5, p. 249. En esta línea, también M. GARCÍA, cit., n. ${ }^{\circ}$ 5, pp. 375 y ss. Sobre la dignidad como bien jurídico, recientemente véase M. ALONSO, cit., n. ${ }^{\circ} 2$, pp. 3 y ss.

${ }^{135}$ Cfr. F. DE LEÓN, cit., n. ${ }^{\circ} 5$, pp. 248 y ss.

${ }^{136}$ F. DE LEÓN, cit., n. ${ }^{\circ}$ 5, p. 250. De otra opinión J. HORTAL, cit., n. ${ }^{\circ}$ 2, p. 479. 
rasgos constitutivos esenciales, en los términos descritos y que de forma genérica sintetizamos en el concepto apuntado de integridad moral» ${ }^{137}$. Finalmente, apunta DE LEÓN VILLALBA la idoneidad de este bien jurídico para la solución de problemas concursales ${ }^{138}$.

Así como el agotamiento del discurso en razones jurídico-formales no determina necesariamente una valoración alta en este plano, tampoco impide que a partir de ese tipo de razones se confieran contenidos éticos a la concreta postura - más allá de la significación ética, no de la argumentación, sino del propio bien jurídico sugerido. En este sentido, la argumentación de DE LEÓN VILLALBA, aunque descansa particularmente en razones sistemáticas y en la estructura de la conducta típica, facilita razones de lesividad y proporcionalidad, en la medida en que favorece una materialización del precepto a partir del «concepto apuntado de integridad moral» ${ }^{139}$. Igualmente, la atención de razones concursales se muestra relevante en los planos sistemático - luego, jurídico-formal - y pragmático pues se trata, también, de la extensión de lo punible —-frente al ilícito administrativo-. Sin embargo, este autor muestra, a su vez, importantes carencias. Incluso al mismo nivel en el que sitúa su discurso. Y es que en la doctrina se ha puesto de manifiesto que el tipo básico pivota «sobre la idea del traslado de personas a nuestro territorio infringiendo los cauces y/o procedimientos legalmente establecidos» ${ }^{140}$. Su aparente extensión semántica, que parece conferir una estructura dual al precepto: promover, favorecer o facilitar el tráfico ilegal o la inmigración clandestina de personas ${ }^{141}$. Se limita considerablemente, mediante la previsión del ánimo de lucro como elemento definidor de uno de los subtipos cualificados: al término «tráfico» no subyace ahí la idea de persona en cuanto mercancía. Y en relación con la otra posible acepción, como sinónimo de «inmigración clandestina», se apunta la ausencia de una relación de necesidad entre el proceso de desnaturalización del inmigrante - y la afección de bienes jurídicos como la integridad moral o/y dignidad humana - «y el hecho de que su entrada y permanencia en el territorio hayan tenido lugar de forma ilegal» ${ }^{142}$. No existe en todos los casos de favorecimiento de inmigración ilegal una necesaria «relación de [...] explotación por parte de quien la favorece» ${ }^{143}$; pero en menor medida aún, una afección de la autodeterminación consciente y responsable de estas personas. Tal déficit jurídico-formal, derivado de la dificultad de ajustarse al verbo típico, se refleja directamente en el nivel de racionalidad pragmática: integridad moral y/o dignidad humana se muestran inidóneos para

${ }^{137}$ F. DE LEÓN, cit., n. ${ }^{\circ}$ 5, p. 250; sobre las diversas consecuencias, véase pp. 251 y ss.

138 F. DE LEÓN, cit., n. ${ }^{\circ}$ 5, p. 252.

${ }^{139}$ Hasta aquí, J. HorTal, cit., n. ${ }^{\circ}$ 2, p. 479. Igualmente, en esta línea C. VillacAmpa, 2004: cit., n. ${ }^{\circ} 5$, p. 186, quien, en relación con el bien jurídico dignidad humana, apunta razones de ultima ratio y proporcionalidad.

140 En este sentido, con razón, J. HORTAL, cit., n. ${ }^{2}$ 2, p. 479, particularmente, pp. 490 y ss.

${ }^{141}$ Críticamente, al respecto M. CANCIO y M. MARAVER, cit., n. ${ }^{\circ} 2$, pp. 348, 352 y ss.; sobre la interpretación jurisprudencial, pp. 360 y ss.; de lege ferenda, pp. 411 y ss.

${ }^{142}$ J. Hortal, cit., n. ${ }^{\circ}$ 2, p. 481. Anteriormente, también M. CANCiO y M. Maraver, cit., n. ${ }^{\circ}$ 2, pp. 372 y ss.: «No existe una relación directa entre el hecho de que se cosifique a los extranjeros, se les convierta en una mera mercancía o, incluso, se abuse de su situación y el hecho de que su entrada o permanencia en el país se produzca de manera ilegal». De otra opinión M. GARCíA, cit., n. ${ }^{\circ}$ 5, pp. 358, 359, 367 y 373, señalando que también, en estos otros casos el inmigrante constituye el «objeto del negocio» $\mathrm{y}$ «se ve sometido a situaciones de dominio, en las que su consentimiento resulta y debe resultar irrelevante para el derecho».

${ }^{143}$ M. CANCIO y M. MARAVER, cit., n. ${ }^{\circ}$ 2, p. 373. 
comprender el ámbito problemático de este precepto. Con otras palabras, si se pretende incriminar determinados comportamientos relativos a la promoción, favorecimiento o facilitación de la inmigración clandestina de personas, y ésta no se caracteriza por el menoscabo de los bienes apuntados, entonces éstos no resultan adecuados — como bienes jurídicos- para una delimitación del ámbito problemático jurídicopenalmente relevante relativo a la inmigración clandestina de personas. Aquí se puede ver un modus tollens:

$$
\begin{aligned}
& p \rightarrow q \\
& \neg q \\
& \neg p ;
\end{aligned}
$$

esto es: «1. Para asumir las ideas de integridad moral y/o dignidad humana como bien jurídico protegido por el art. 318 bis del Código Penal español, entonces, éstas deben favorecer la comprensión de lo injusto propio de las conductas relativas a la inmigración clandestina de personas. 2. Las ideas de integridad moral y/o dignidad humana no caracterizan significativamente la inmigración clandestina de personas. Por tanto 3. las ideas de integridad moral y/o dignidad humana no fungen como bien jurídico protegido del art. 318 bis del Código Penal español».

En un trabajo anterior he sugerido como bien jurídico protegido para el art. 318 bis de nuestro Código Penal los derechos de los ciudadanos extranjeros, mediante una argumentación próxima a la petición de principio que se agotaba en una referencia al título donde se ubica este precepto ${ }^{144}$. Más fundadamente, NAVARRO CARDOSO llega a esta misma conclusión sobre diversas clases de premisas ${ }^{145}$. A nivel ético apunta razones de lesividad, «al Derecho penal no le compete función ordenadora alguna de políticas estatales [...] y si actuase guiado por esa finalidad, no estaría generando más que delitos formales (caracterizados en este caso, por elevar a la categoría de delito el quebrantamiento de normas administrativas)» ${ }^{146}$; fragmentariedad, «no es misión del Derecho penal la ordenación de sectores, ni debe convertirse en "brazo armado" de la legislación de extranjería»; así como, en menor medida, razones de proporcionalidad en sentido estricto, «es a partir de ese objeto de tutela cuando debe dotarse al tipo penal de un contenido de injusto material mínimo para justificar el merecimiento de la intervención jurídico-penal» ${ }^{147}$. E igualmente insiste en el carácter indiciario de la rúbrica

${ }^{144}$ Cfr. F. SÁNCHEZ, cit., n. ${ }^{\circ} 22$, p. 289.

145 F. NAVARRO, 2002: «Observaciones sobre los delitos contra los derechos de los ciudadanos extranjeros», Revista Penal, 10, p. 45. Anteriormente, también M. RoDRÍGUEZ, cit., n. ${ }^{\circ}$ 8, p. 58, donde identifica como bien jurídico «el estatus jurídico del extranjero: los derechos y libertades reconocidos al mismo por el ordenamiento jurídico español», matizando, p. 60, que «no se protege a los extranjeros en cuanto individuos aislados, sino como colectivo social titular de una serie de derechos». Críticamente, con carácter general, también F. MUNOZ, cit., n. ${ }^{\circ}$ 99, p. 355.

146 F. NAVARRO, cit., n. ${ }^{\circ}$ 145, p. 45, apuntando igualmente que «sólo deben tener la consideración de bienes jurídico-penales aquellos que atañen al contenido esencial de un derecho fundamental, no participando de esta naturaleza el control de los flujos migratorios, y sí los derechos fundamentales de los ciudadanos extranjeros».

147 Ibídem, e igualmente, en p. 46: las infracciones «calificadas como delito deben contener mayor cantidad de injusto material por ser más peligrosas respecto de la indemnidad del bien jurídico protegido». En esta línea, véase SAP 15/2001 Málaga, Melilla, de 13 de marzo, fundamento de derecho primero, señalando sobre tales razones, la necesidad de atender a la esfera jurídica del ciudadano extranjero, concluyendo así: «El 
del Título XV bis a un nivel sistemático ${ }^{148}$. Sin embargo, a la hora de concretar el haz de derechos protegidos mediante este precepto, el autor diferencia tres conjuntos: derechos que corresponden por igual a españoles y extranjeros como la vida, la salud, etcétera; derechos vinculados a la nacionalidad como los derechos de sufragio activo y pasivo, entre otros; $\mathrm{y}$ «derechos cuya titularidad ostentan los españoles y que pueden ostentar los extranjeros, siempre que exista una previsión legislativa en ese sentido, la cual debe respetar, en ese caso, las prescripciones constitucionales» ${ }^{149}$. NAVARRO CARDOSO excluye los dos primeros grupos del ámbito de protección del art. 318 bis. Así, en relación con los primeros, derechos que corresponden por igual a españoles y extranjeros, arguye que ya han sido elevados a la categoría de bienes jurídicos en otros lugares del Código y leyes penales especiales ${ }^{150}$. Seguidamente, también, descarta los derechos vinculados a la nacionalidad: «Su titularidad sólo la ostentan los españoles, en una suerte de exclusión de los extranjeros» ${ }^{151}$. Y llega, así, a la conclusión de que el haz de derechos protegidos en este precepto son «los denominados derechos sociales, y [...] los llamados derechos políticos no exclusivos de los nacionales (al menos, en una primera lectura de la Constitución), esto es, los derechos de reunión y manifestación, asociación, sindicación y huelga» ${ }^{152}$. De esta forma, NAVARRO termina aproximándose a la posición de autores como SERRANO-PIEDECASAS, y se expone con ello, al mismo aparato crítico.

Según esta comprensión, por ilustrarla con un ejemplo, si un ciudadano esconde «en la parte trasera de la furgoneta, en el hueco de una mesa que allí iba y oculta tras otros muebles y mantas a una mujer de nacionalidad marroquí llamada Virginia [...], y al hijo de ésta de una edad aproximada de un año y siete meses de edad, a quienes trataba de introducir en España conociendo que carecían de cualquier documentación que les habilitara para entrar o permanecer en territorio nacional» ${ }^{153}$, su conducta debe entenderse como una lesión o puesta en peligro de —entre otros- los derechos de reunión, manifestación, sindicación y huelga de estos ciudadanos ${ }^{154}$. La misma tesis debiera explicar materialmente la tipicidad de la conducta de quien, por poner otro ejemplo, trata de facilitar la entrada «a sesenta y ocho inmigrantes de origen subsahariano» ${ }^{15}$ presentes ya irregularmente en aquel país, Marruecos. Las dudas que suscitan estos ejemplos responden a varias razones. Por una parte, el traslado físico e irregular de estos ciudadanos a España sólo puede entenderse como un favorecimiento - frente a una situación de irre-

bien jurídico protegido por la misma no es otro por tanto que el disfrute de aquellas libertades públicas más que el control por parte del Estado del mercado de trabajo y de la presencia de súbditos extranjeros en España».

${ }^{148}$ F. NAVARRO, cit., n..$^{\circ}$ 145, p. 45. En esta línea, también M. RodRíGUEZ, cit., n. ${ }^{\circ}$ 8, p. 55, quien apunta igualmente «la ubicación sistemática del delito, inmediatamente después del Título en el que se protegen los derechos de los trabajadores, y entre los que también se otorga protección a los derechos de los trabajadores no nacionales frente al abuso de mano de obra extranjera y la inmigración clandestina».

${ }^{149}$ F. NAVARRO, cit., n. ${ }^{\circ} 145$, p. 48.

${ }^{150}$ F. NAVARRO, cit., n. ${ }^{\circ} 145$, p. 49.

${ }^{151}$ F. NAVARRO, cit., n. ${ }^{\circ} 145$, p. 47

${ }^{152}$ F. NAVARRO, cit., n. ${ }^{\circ} 145$, p. 49 , mostrando sus dudas sobre la constitucionalidad de los limites al ejercicio de estos derechos que introduce la Ley Orgánica 4/2000. Confirmando en buena medida esta lectura, recientemente véase STC 236/2007, de 7 de noviembre, fundamentos de derecho sexto, séptimo y noveno.

${ }_{153}$ STS 526/2007, de 6 de junio, antecedente primero.

${ }^{154}$ Cfr. F. NAVARRO, cit., n. ${ }^{\circ} 145$, p. 49.

155 STS 622/2007, de 5 de julio, antecedente primero. 
gularidad en Marruecos- para el futuro ejercicio de ésos y otros derechos de conformidad con lo dispuesto en nuestro marco jurídico: cuando menos, una vez aquí, ello torna físicamente posible ${ }^{156}$. Pero es que por otra parte, cabe señalar que tales derechos como los de reunión y asociación, corresponden en nuestro ordenamiento jurídico «a cualquier persona, independientemente de la situación en que se encuentre» ${ }^{157}$. Y en cuanto a las concretas limitaciones inesenciales derivadas de la situación de irregularidad, el art. 31.3 de la citada Ley Orgánica 4/2000 prevé la posibilidad de «conceder una autorización de residencia temporal por situación de arraigo, así como por razones humanitarias, de colaboración con la Justicia u otras circunstancias que se determinen reglamentariamente», a quienes, entre otros supuestos, como consecuencia de su entrada irregular no sean titulares de tal autorización para residir ${ }^{158}$. Luego, no parecen ser éstos los derechos perjudicados a través de la promoción, favorecimiento o facilitación de la inmigración ilegal de personas desde, en tránsito o con destino a nuestro país.

Con ello sólo restan «los derechos que conforman un estándar mínimo, que dispersos a lo largo del Título I de la Constitución y agrupados en razón de un interpretación sistemática de su contenido [...] corresponden por igual a españoles y extranjeros» ${ }^{159}$, esto es, el derecho a la vida, integridad física o el patrimonio, por poner tres ejemplos. Sin embargo, «todos estos intereses ya están elevados a la categoría de bienes jurídicopenales, recibiendo tutela penal específica (homicidio, lesiones, etc.) $\gg^{160}$. Surge la duda sobre el sentido de una ulterior tutela normativa mediante este art. 318 bis. Hace algunos años apuntaba la especial vulnerabilidad de este colectivo en cuanto razón de esta específica tutela normativa ${ }^{161}$. También para la exclusión de los ciudadanos nacionales del ámbito de protección de la norma ${ }^{162}$. Entiendo que tales razones siguen resultando vigentes. Pues no son ciudadanos españoles o comunitarios quienes se muestran dispuestos a sentarse «en una débil embarcación ocupada por entre 20 y 30 personas más» con destino a España, por poner un ejemplo ${ }^{163}$. Ciertamente, el apdo. 3 del art. 318 bis

${ }^{156}$ En esta línea, también M. CANCIO y M. MARAVER, cit., n. ${ }^{\circ}$ 2, p. 369: «Parece complicado afirmar que se protegen los derechos que el extranjero hubiera tenido si la entrada se hubiera producido de manera legal, cuando la situación de ese extranjero se caracteriza, precisamente, por la imposibilidad de entrar de manera legal. El bien jurídico protegido, en definitiva, no puede estar representado por unos derechos que no existen»; E. GARCÍA y J. RODRÍGUEZ, cit., n. ${ }^{\circ}$ 10, p. 728; J. HORTAL, cit., n. ${ }^{\circ}$ 2, p. 477 , apuntando que el sujeto pasivo percibe la conducta típica «como un bien que les permite dejar atrás situaciones de extrema miseria». Ultimamente, también J. LACRUZ, cit., n. ${ }^{\circ} 2$, p. 21, apuntando en esta línea que «la propia ley de extranjería reconoce un gran número de derechos a los extranjeros que se encuentran en situación irregular en España, entre los que se encuentran los de tipo educativo y sanitario».

157 STC 236/2007, de 7 de noviembre, fundamentos de derecho sexto y séptimo, respectivamente.

${ }^{158}$ Ley Orgánica 4/2000, cit., n. ${ }^{\circ} 37$.

159 Excluidos, claro está, los derechos vinculados a la nacionalidad, F. NAVARRO, cit., n. ${ }^{\circ} 145$, p. 47. En sentido contrario, M. RODRÍGUEZ, cit., n. ${ }^{\circ} 8$, p. 55.

${ }_{160}$ F. NAVARRO, cit., n. ${ }^{\circ} 145$, p. 49.

161 En esta línea también A. PÉREZ, 2006: cit., n. ${ }^{\circ}$ 5, p. 119.

162 Aun cuando se trata de bienes de los que estos también son titulares, F. SÁNCHEZ, cit., n. ${ }^{\circ} 22$, p. 289. En esta linea también, en relación con ciudadanos comunitarios, STS 484/2007, de 29 de mayo, fundamento de derecho segundo. En nuestra doctrina, M. GARCÍA, cit., n. ${ }^{\circ} 127$, p. 1333, para quien «ello viene impuesto por la rúbrica del Título [...] y por el propio sentido de este tipo penal, en el que se exige la infracción de trámites de traspaso de fronteras sólo atribuibles a extranjeros»; M. RODRÍGUEZ, cit., n. ${ }^{\circ} 8$, p. 72, para quien «en virtud de lo dispuesto en la rúbrica del Título los nacionales españoles no puedan ser sujetos pasivos del delito», excluyendo incluso a los extranjeros en condiciones de acceder a los permisos de entrada o permanencia (cfr. pp. 64 y 73). De otra opinión J. LACRUZ, cit., n. ${ }^{\circ} 2$, pp. 32 y ss.

163 SAP Las Palmas 48/2004, de 22 marzo, fundamento de derecho tercero. 
empuja a ulteriores discriminaciones. La introducción del ánimo de lucro como circunstancia cualificante en este tercer apartado no sólo impide asignar al termino «tráfico ilegal» una significación distinta que a «inmigración clandestina» ${ }^{164}$, también la comprensión de los intereses patrimoniales como bien jurídico protegido ya en el tipo básico de este precepto. Frente a ello la cláusula «poniendo en peligro la vida, la salud o la integridad de las personas» se presta a ulteriores matizaciones. En concreto, una interpretación del tipo básico, siguiendo la concepción mayoritaria, como delito de peligro abstracto de forma que se entiende consumado cuando de la realización del juicio de peligro, esto es, «una persona inteligente (el juez) colocada en la posición del autor, en el momento de la acción y teniendo en cuenta todas las circunstancias del caso concreto cognoscibles por esa persona inteligente, más las conocidas por el autor (saber ontológico) y la experiencia común de la época sobre cursos causales (saber nomológico)» ${ }^{165}$, cabe inferir que la producción del resultado - la lesión de tales bienes personales: «la vida, la salud o la integridad de las personas»- no era consecuencia absolutamente improbable de la conducta típica. Mientras que en el tipo agravado cabe exigir un resultado de peligro, esto es, la concreción en el supuesto enjuiciado de los distintos factores que sustentan positivamente el juicio de peligro ${ }^{166}$.

A las anteriores razones, cabe añadir diversas formas de argumentos. Por una parte, la interpretación expuesta facilita la interrelación del tipo básico con los subtipos agravados del art. 318 bis, particularmente con su cláusula tercera, según el grado de concreción del riesgo generado por la conducta típica para los bienes propuestos. También la discriminación entre injusto punible e ilicito administrativo, en la medida en que la infracción administrativa muy grave, prevista en el art. 54.1.b) conforma una estructura típica a partir del «ánimo de lucro» o la pertenencia a «una organización» ${ }^{167}$. Luego, si una ciudadana española, cuando se disponía a embarcar con destino a la península, «al llegar al control policial de identificación de pasajeros, exhibe a los Agentes Policiales su documentación de identidad y las de sus hijas Leticia y Silvia, esta última nacida en 1990 y que no viajaba con la acusada», tratándose en realidad de «Emilia de nacionalidad marroquí carente de documentación administrativa para acceder a territorio español», a la que pretendía introducir irregularmente en el mismo, no nos encontraríamos en el margen del art. 318 bis del Código Penal español, en la medida en que la conducta no afecta a los bienes señalados ${ }^{168}$. Tampoco, si en el momento de proceder al embarque «con dirección a la Península, en el control de registro de vehícu-

${ }^{164}$ Cfr. n. ${ }^{\circ} 142$.

165 J. CEREZO, cit., n. ${ }^{\circ} 85$, p. 113.

166 J. CEREZO, cit., n. ${ }^{\circ} 85$, p. 114.

167 Art. 54.1.b) Ley Orgánica 4/2000, cit., n. ${ }^{\circ}$ 37: «Inducir, promover, favorecer o facilitar con ánimo de lucro, individualmente o formando parte de una organización, la inmigración clandestina de personas en tránsito o con destino al territorio español o su permanencia en el mismo, siempre que el hecho no constituya delito»; igualmente véanse arts. 54.2.a) y b) del citado texto.

${ }_{168}$ De otra opinión SAP 20/2005 Málaga, Melilla, de 1 de abril, considerando, no obstante, mediante la aplicación de la atenuante específica del número 6 de este artículo, «la menor gravedad del hecho derivada de la escasa peligrosidad social de la dinámica comisiva que se concreta en un intento de engaño mediante la generación en los Agentes de un error en la persona cuya inmigración se pretende. Careciendo la actitud engañosa de la realidad suficiente para provocar el error como evidencia el hecho del fácil descubrimiento por los Agentes Policiales de la no correspondencia de la identidad entre la persona y el documento con el que se trata de identificar a ésta». Igualmente vid. SAP 10/2003 Málaga, Melilla, de 12 de febrero, fundamento de derecho segundo, recurriendo aquí a la circunstancia de parentesco. 
los, agentes de la Guardia Civil [...] descubr(en) en el espacio existente entre el respaldo de los asientos delanteros y traseros, oculto en el suelo del turismo y debajo de unas mantas a Gonzalo [...], súbdito marroquí (que) carece de autorización administrativa para acceder a territorio de la Comunidad Europea» ${ }^{169}$. Por el contrario, si «los individuos transportados se encontraban ocultos en un doble fondo practicado en la furgoneta de dimensiones ostensiblemente reducidas y de escasa ventilación (obsérvese tan solo tres agujeros en la parte inferior del vehículo que se encontraban tapados por el propio cuero cabelludo de los inmigrantes...). El agente que los interceptó reconoce que los inmigrantes no pudieron salir por sus propios medios, que precisaron de su propia colaboración y ostensiblemente entumecidos; en definitiva que en ningún caso reúne las condiciones mínimas de seguridad para transportar a las cuatro personas que viajaban en el vehículo, poniendo, por ello, en grave peligro la vida de los pasajeros» ${ }^{170}$; se advierten ya los elementos que nos sitúan dentro del margen de lo jurídico-penalmente relevante. También, si se efectúa un traslado desde el «continente africano a Lanzarote [...] en una embarcación y condiciones de ocupación, vestimenta, ausencia de medidas de seguridad, etc.» que incrementa o puede incrementar «el riesgo de la travesía hasta convertirla en un reto de supervivencia» ${ }^{171}$, dependiendo de la concreción de estos factores de riesgo - esto es, que los medios y circunstancias del viaje conviertan éste, efectivamente, en un reto de supervivencia- que nos movamos en el marco del tipo básico o cualificado del número tercero del art. 318 bis. Según la estructura expuesta, el grado de peligro — concreto o abstracto- así como, en términos negativos, la ausencia del mismo ofrecen una explicación material de su comprensión en el tipo cualificado, básico o como mero ilícito administrativo, respectivamente ${ }^{172}$. Estos argumentos jurídico-formales permiten una fácil traducción en términos éticos: atienden, en particular, a razones de lesividad, fragmentariedad y proporcionalidad en sentido estricto ${ }^{173}$. También en términos teleológicos, en la medida en que trata de reconducir lo punible — pese a la lamentable técnica legislativa— a lo «que se debiera perseguir». En términos pragmáticos, no parece que el uso del instrumental jurídico-penal deba ir más allá en la regulación de la entrada y salida ilegal de extranjeros en un marco normativo donde el ánimo de lucro juega como circunstancia cualificante. Y se mueven, como las demás posturas, en los márgenes de lo semánticamente posible. En cualquier caso, éstas no son más que mis razones, y como todo lo expuesto, esbozadas provisionalmente y en espera de mejores soluciones y argumentos ${ }^{174}$. Y es que el desarrollo de una te-

${ }^{169}$ De otra opinión SAP 25/2007 Málaga, Melilla, de 19 de abril, hechos probados. Críticamente, sobre este y otros supuestos, M. CANCIO y M. MARAVER, cit., n. ${ }^{\circ}$ 2, p. 407.

170 SAP 73/2005 Málaga, Melilla, de 28 de septiembre, fundamento de derecho primero.

171 SAP 48/2004 Las Palmas, de 22 de marzo, fundamento de derecho tercero.

172 En esta línea también STS 484/2007, de 29 de mayo, fundamento de derecho segundo: «El interés del Estado en el control de los flujos migratorios, ya protegido mediante la acción administrativa, sólo encuentra protección penal si los derechos de los ciudadanos extranjeros se ven seria y negativamente afectados por la conducta, sea de modo actual y efectivo o al menos ante un riesgo de concreción altamente probable [...] es precisa una afectación, real o potencial, de los derechos del ciudadano». En nuestra doctrina, M. GARCÍA, cit., n. ${ }^{\circ}$ 127, pp. 1327, 1328 y 1336, apuntando algunas lagunas de punibilidad; E. GARCÍA y J. Rodríguez, cit., n. ${ }^{\circ}$ 10, pp. 733 y ss.; C. VillaCAmPA, 2005: cit., n. ${ }^{\circ}$ 5, p. 1670. Desde otra postura, J. HoRTAL, cit., n. ${ }^{\circ}$ 2, p. 493, n. 54. Con carácter general, ilustrativo J. CEREZO, cit., n. ${ }^{\circ}$ 38, pp. 60 y ss.

${ }^{173}$ Cfr. J. DíEZ, cit., n. ${ }^{\circ} 18$, pp. 136 y ss.

${ }^{174}$ Con carácter general, véase R. ALEXY, cit., n. ${ }^{\circ} 23$, pp. 141 y 279. En relación con los presupuestos valorativos, también N. MACCORMICK, cit., n. ${ }^{\circ}$ 30, p. 18: «No deberíamos suponer que nuestras actuales concep- 
oría de la argumentación jurídica no ambicionaría ofrecer «la solución correcta», sino simplemente, racionalizar en alguna medida la inevitable mutabilidad de lo jurídico o, parafraseando al profesor de Kiel, este «imprescindible tributo que» nuestra materia, con sus ideales y conceptos, tiene «que pagar a cambio del triunfo, nunca suficientemente apreciado, de su institucionalización en el mundo, tal como es» ${ }^{175}$.

ciones de la racionalidad no puedan mejorar y desarrollarse en el futuro de forma que cambien y amplíen las fronteras de la racionalidad». Igualmente ilustrativo J. GARCíA AMADO, cit., n. ${ }^{\circ}$ 91, p. 178.

${ }^{175}$ R. AleXY, cit., n. ${ }^{\circ} 43$, p. 64. Igualmente A. AARNIO, cit., n. ${ }^{\circ} 47$, p. 112. Escéptico, sin embargo, señala la mayor seguridad del modelo sistemático frente a un modelo argumentativo que se agota en pretensiones retóricas, J.-M. SILVA., cit., n. ${ }^{\circ}$ 70, p. 658. Anteriormente, también J. HruSCHKA, 1984: cit., n. ${ }^{\circ}$ 42, p. 9. 